\title{
Exploring multiple eco-routing guidance strategies in a commuting corridor
}

Jorge M. Bandeira.

University of Aveiro, Centre for Mechanical Technology and Automation / Dep. Mechanical Engineering

Campus Universitário de Santiago, 3810-193 Aveiro - Portugal

Phone: $\quad(+351) \quad 234 \quad 370 \quad 830$, Fax: $\quad(+351) \quad 234 \quad 370 \quad 953, \quad$ E-mail: jorgebandeira@ua.ptmailto:jorgebandeira@ua.pt

mailto:jorgebandeira@ua.pt

Paulo Fernandes

University of Aveiro, Centre for Mechanical Technology and Automation / Dep. Mechanical Engineering

Campus Universitário de Santiago, 3810-193 Aveiro - Portugal

Phone: $\quad(+351) \quad 234 \quad 370 \quad 830$, Fax: $\quad(+351) \quad 234 \quad 370$ 953, E-mail: paulo.fernandes@ua.ptmailto:paulo.fernandes@ua.pt

mailto:paulo.fernandes@ua.pt

Tânia Fontes

INESC TEC - INESC Technology and Science and FEUP - Faculty of Engineering, University of Porto

Rua Roberto Frias, 4200-465, Porto, Portugal

Phone: (+351) 229578710 E-mail: trfontes@fe.up.pt

Sérgio Ramos Pereira.

University of Aveiro, Centre for Mechanical Technology and Automation / Dep. Mechanical Engineering

Campus Universitário de Santiago, 3810-193 Aveiro - Portugal

Phone: $\quad(+351) \quad 234 \quad 370 \quad 830$, Fax: $\quad(+351) \quad 234 \quad 370 \quad 953, \quad$ E-mail: sergiofpereira@ua.ptmailto:sergiofpereira@ua.pt

mailto:sergiofpereira@ua.pt

Asad J. Khattak

University of Tennessee, 322 J.D. Tickle Bldg., Knoxville, TN 37996-2010

Phone: (865) 974-7792; E-mail: akhattak@utk.edu

Margarida C. Coelho.

University of Aveiro, Centre for Mechanical Technology and Automation / Dep. Mechanical Engineering

Campus Universitário de Santiago, 3810-193 Aveiro - Portugal

Phone: (+351) 234370 830, Fax: (+351) 234370 953, E-mail: margarida.coelho@ua.pt 
February 2017 Submitted for consideration for publication at the International Journal of Sustainable Transportation

\begin{abstract}
The introduction of eco-routing systems has been suggested as a promising strategy to reduce carbon dioxide emissions and criteria pollutants. The objective of this study is to scrutinize the impacts of an eco-routing guidance system on emissions through the use of a case study in a commuting corridor. This research aims at assessing the potential environmental benefits in terms of different pollutant emissions. Simultaneously, it addresses the extent of variations in system travel time that each eco-routing strategy implies. The methodology consists of three distinct phases. The first phase corresponded to the adjustment of a micro simulation platform of traffic and emissions with empirical data previously collected. Secondly, volume-emission-functions (VEF) were developed based on the integrated modelling structure. Finally, different scenarios of traffic flow optimization were performed at the network level based on a simplified assignment procedure. The results show that if the traffic assignment is performed with the objective of minimize overall impacts, total system environmental damage costs can be reduced up to $9 \%$ with marginal oscillations in total system travel time. However, if drivers are advised based on their own emissions minimization, total system emissions may be higher than under the standard user equilibrium flow pattern. Specifically, environmentally friendly navigation algorithms focused on individual goals may tend to do divert traffic to roads with less capacity affecting the performance of the remaining traffic. This case study brings new insights about the difficulties and potentials of implementing such systems.
\end{abstract}

Keywords: Eco-routing, traffic management, emissions, microscopic modeling 


\section{INTRODUCTION AND RESEARCH OBJECTIVES}

The magnitude of the impacts in the transport sector due to the recent drop in crude oil prices ("oilprice.com," 2016.) is not yet clear. However, it appears to be highly likely that fossil fuels will still dominate the road transport energy usage by 2050 (-EC, 2011). In fact, despite technological improvements in the automotive sector, it can take years before the vehicle fleet will be renewed and an effect of reduced fleet emissions will be evident (Sundvor et al., 2012). Furthermore, one must take into account that one of the dominant sources of air pollution affecting environmental living quality in urban areas is road traffic-induced air pollution.

The above mentioned facts mean that other traffic measures such as behavioral changes allowing a smarter spatial distribution of traffic flows and consequent increase of network efficiency are needed (EC, 2011). In this context, noteworthy progress has been made in developing eco-routing navigation systems, which its main objective is to propose a route that uses the least amount of fuel and/or produces the least amount of emissions (Boriboonsomsin, Joseph, \& Barth, 2014).

Besides urban sustainability plans, European authorities are making efforts to stimulate companies that generate a significant traffic demand (large enterprises, hospital facilities, universities and others), in developing specific mobility plans to ensure that journeys undertaken by employees and visitors to their facilities generate a minimum economic, social and environmental impacts (Action Plan on Urban Mobility - State of Play, 2012). In this context, innovative eco-routing systems may play an important role when the choice of soft modes is not feasible.

The majority of studies have identified a great potential for emissions reduction based on an appropriate route choice regardless of the emissions methodology used. To estimate the impacts of eco-routing systems, former studies (Benedek \& Rilett, 1998; Gwo Hshiung \& Chien-Ho, 1993; Rilett \& Benedek, 1994) applied average speed-based emissions models. 
However, there is an increasing trend for using instantaneous emissions models to evaluate the environmental consequences of route selection (Kyoungho Ahn \& Rakha, 2013; Boriboonsomsin, Barth, Zhu, \& Vu, 2012; Frey, Zhang, \& Rouphail, 2008a; Guo, Huang, \& Sadek, 2013; Jorge M. Bandeira et al., n.d.; Zhang, Lv, \& Ying, 2010). Instantaneous emission models (such as VSP/MOVES, CMEM, VT-micro) clearly include congestion in the modeling process, but for average speed models (such as COPERT), this could not be determined directly (Smit, Brown, \& Chan, 2008).

Recently, the wide-impact of green routing systems is being assessed based on simulation of real networks. Guo et al. (2013) developed an integrated platform combining TRANSIMS and MOVES to investigate the impact of market penetration of eco-routing systems. The analysis indicates that the eco-routing strategies can achieve significant environmental benefits, at relatively low penetration rates and without a significant increase in travel time. Using the INTEGRATION software, (Kyoungho Ahn \& Rakha, 2013) a study evaluated the system-wide impacts of using eco-routing strategies within two large networks. The authors found that eco-routing vehicles did not save always fuel when compared to the standard User Equilibrium (UE). Based on the CMEM model, a study pointed out that when the effects of turning movements and acceleration are discarded, sub-optimal routes for eco-drivers are created (Nie \& Li, 2013). By integrating the macroscopic Dynamic Traffic assignment simulator (DTA) and the ARTEMIS emission model, no single solution optimizing all traffic externalities was found (Wismans, Berkum, \& Bliemer, 2013). Using also a DTA model to evaluate fuel-saving assignment policies, (Levin et al, 2014) a study has shown that to achieve system-level energy savings, very complex assignment strategies are required.

In summary, previous research shows that the introduction of eco-routing systems can lead to significant emissions reduction at least for individual drivers. However, the implementation of eco-traffic assignment policies over a whole urban network may lead to contradictory results. Specifically, an increase in system emissions is recurrently observed after the implementation of these systems (Ahn, Rakha, \& Moran, 2011; Levin et al., 2014). Nonetheless, the complexity of the models, the black box nature of some of them, and the multiplicity of Origin-Destination (O/D) pairs hinders the understanding of internal driver's 
behavior and identifying where the greatest inefficiencies in the eco-traffic assignment process come from.

This paper differs from previous research in the following aspects:

- Traffic assignment conducted externally allowing a datelined assessment of network equilibrium and major trends under multiple eco-routing strategies;

- Development of detailed road segment performance functions based on an integrated microscopic traffic-emissions platform which has been previously calibrated with an extensive database of global navigation satellite system (GNSS) data;

- Integration of multiple environmental criteria for road network optimization (both from the individual and system point of views).

Specifically the main contributions of this paper are to:

- Simulate the existence of a centralized Traffic Management Centre (TMC) advising a subpopulation of eco-routing commuters based on environmental criteria;

- Contribute for understanding the network equilibrium and how system travel times, and different pollutant emissions and fuel consumption may change when a subpopulation of drivers follow multiple eco-routing strategies;

- Exploit the potential of microscopic tools to improve traffic management operations by describing the environmental impact of different levels of demand at link level.

\section{METHODOLOGY}

\subsection{Basic Framework and study assumptions}

To answer the growing need of developing specific mobility plans for institutions generating high demand for passenger's mobility, this study proposes the implementation of a traffic 
management system advising a certain volume of eco-routing vehicles ( $\mathrm{q}_{\mathrm{er}}$ ) based on environmental criteria. In such scenario, drivers would receive voluntarily the indication of which route they should follow during the commute to minimize emission impacts. The main objective of this work is to understand the network equilibrium under different routing objectives when a group of drivers with a common destination follows multiple assignment strategies.

Figure 1 shows the main steps of the methodology, which is divided, into three main stages. The first part comprises previously developed and published work of the research team and it includes the description of an extensive empirical GNSS database collected in the city of Aveiro and (Bandeira et al., 2016) which has been used to calibrate and validate micro simulation platform of traffic and emissions (presented in Fontes et al 2014). 


\section{EMPIRICAL DATA COLLECTION (NETWORK LEVEL)}

2 BASELINE MODEL

EVALUATION

(ROAD SEGMENT LEVEL)

\section{ECO-ROUTING \\ SCENARIOS \\ (NETWORK LEVEL)}

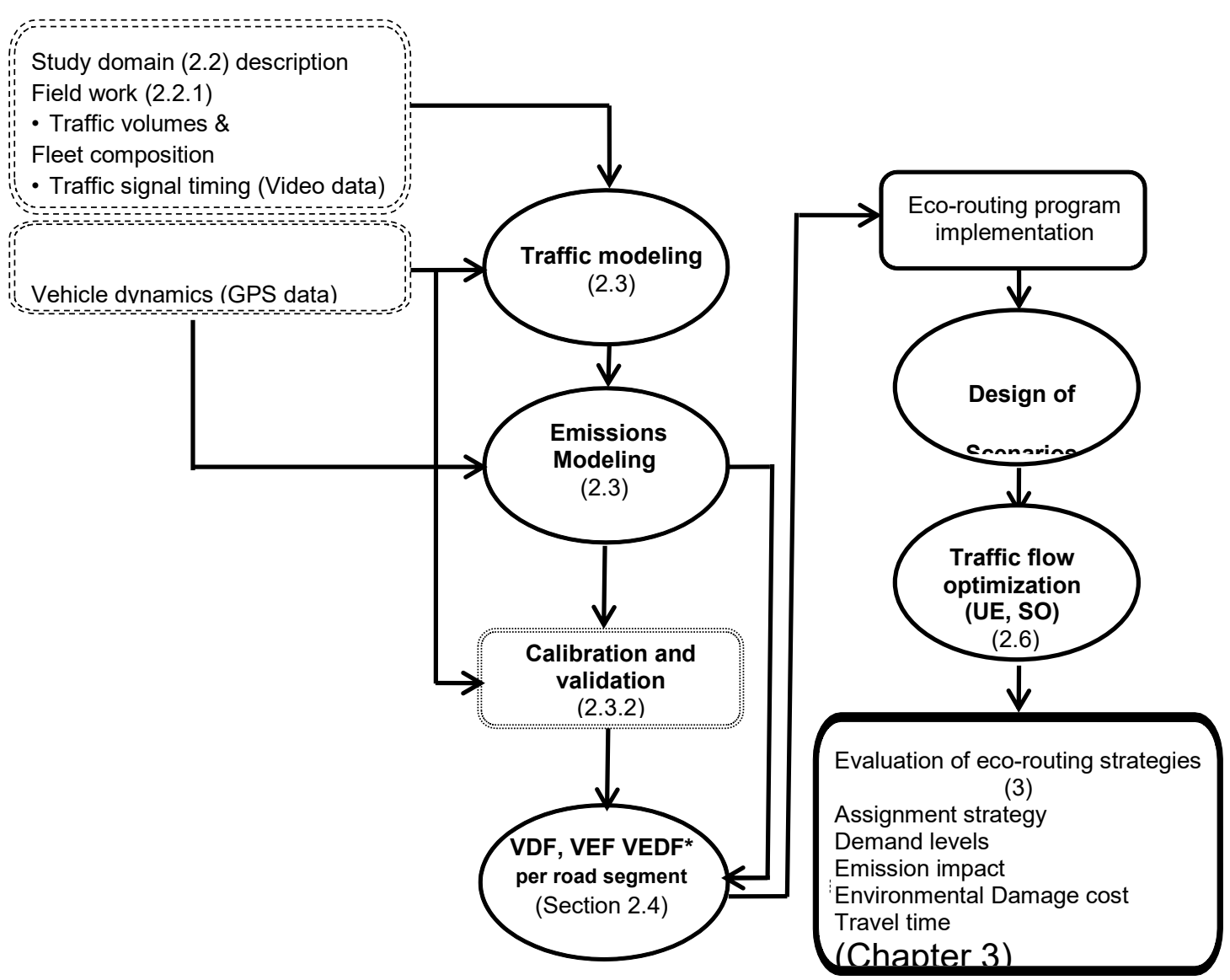

*(VDF - Volume Delay Functions, VEF - Volume Emission Functions, VEDF - Volume Environmental Damage Function) Boxes with dotted outline include tasks previously described in other publications (Bandeira et al 2016, Fontes et al 2014)

\section{FIGURE 1 Overall methodology.}

In order to establish a methodology for analyzing and optimizing the performance of the network in a more efficient and expeditious way, road segment-based environmental performance functions were developed. The processes for generation of these functions are explained in section 2.4. Several scenarios related with the implementation of eco-routing 
policies were performed under different levels of acceptance, routing strategies, and network saturation (see section 2.5) The third stage is devoted to explain the process of network optimization under multiple eco-routing strategies (section 2.6).

\section{Study assumptions}

Generally, drivers are more concerned about travel time than travel distance as they value their time (Boriboonsomsin et al., 2014). Furthermore, when provided with eco-routing alternatives, the majority of the drivers would prefer the least fuel consumption/carbon dioxide $\left(\mathrm{CO}_{2}\right)$ option than the other least emission criteria (Boriboonsomsin et al., 2014). Therefore, to increase and make more realistic the acceptance of the proposed system, it is assumed that commuters could receive an incentive such as electronic card-bonus transferable to use in different contexts such is suggested in (Ayyildiz \& Willenbrock, 2010).

The assignment of eco-routing vehicles is executed by using new-developed environmental performance functions. Since these functions are developed based on a pre-established group of traffic demand scenarios, the evaluation of cases of unexpected congestion and incidents during each trip it is beyond the scope of this paper.

It is also considered that traffic oscillations on secondary links have negligible influence on the performance of the evaluated routes. It seems reasonable to assume that traffic dynamics are mainly conditioned by the observed flow on each link because the work is focused on main roads where the transition between them is generally performed with segregated lanes. However, the average delay caused by midway intersections is intrinsically considered in the performance functions designed ad-hoc for each road segment. In this paper "link" is considered as the basic element of the simulated city transport network in the traffic model. A "road segment" may include multiple links (e.g. road section with different numbers of lanes) and it refers to the road sections connecting the main nodes of the network (ABCDEFH).

The assessment of network performance only reproduces the immediate impacts of the evaluated eco-routing approaches. That is, the effect of shifting a population of eco-routing vehicles to a suggested eco-friendly route is evaluated without additional considerations 
related to the driver's' reaction to new traffic conditions in subsequent days. Moreover, promoting flow distribution changes in a given corridor may affect not only the travel time on the considered links, but also in the adjacent links and inevitably outside the border of the study area. In the analysed simulation period, it is assumed that the vehicles using the links under study with other destinations keep the same behaviour.

The environmental performance functions are based on a generic vehicle representative of the local fleet characteristics. Future research may consider the effect of selecting a specific route according to individual vehicle features.

\subsection{Study domain}

The study corridor is located over a representative medium-sized European city, (Aveiro, Portugal 77,700 inhabitants) (INE, 2012). Some characteristics observed in this type of cities make these sites particularly attractive case studies to test eco-routing applications:

1) Providing public transport in relatively low-density areas is usually cost-inefficient and the mobility tends to be dominantly provided by / individual transportation;

2) Notwithstanding the lower absolute traffic volumes when compared to large cities, road traffic remains a major contributor to harmful air pollution (Bandeira, Coelho, Sá, Tavares, \& Borrego, 2011)

3) Reduced occurrence of high congestion levels. This means that there is higher potential for the traffic manager focusing on other optimization objectives rather than relief congestion and travel time.

A local O/D survey has shown that the main point of attraction (D) during the morning peak hour (8:15-9:15) is located in the south of the urban centre (University campus/Central Hospital). Significant part of commuters lives in the Northeast of this area and they have to cross or bypass the urban core to reach this destination. Therefore, this O/D pair is an interesting case study given its relatively high demand and impact on urban traffic, as well 
as the diversity of the characteristics of the available routes. Figure 2 shows the network map, the main alternative routes (R1-R4) and the main road segment characteristics.

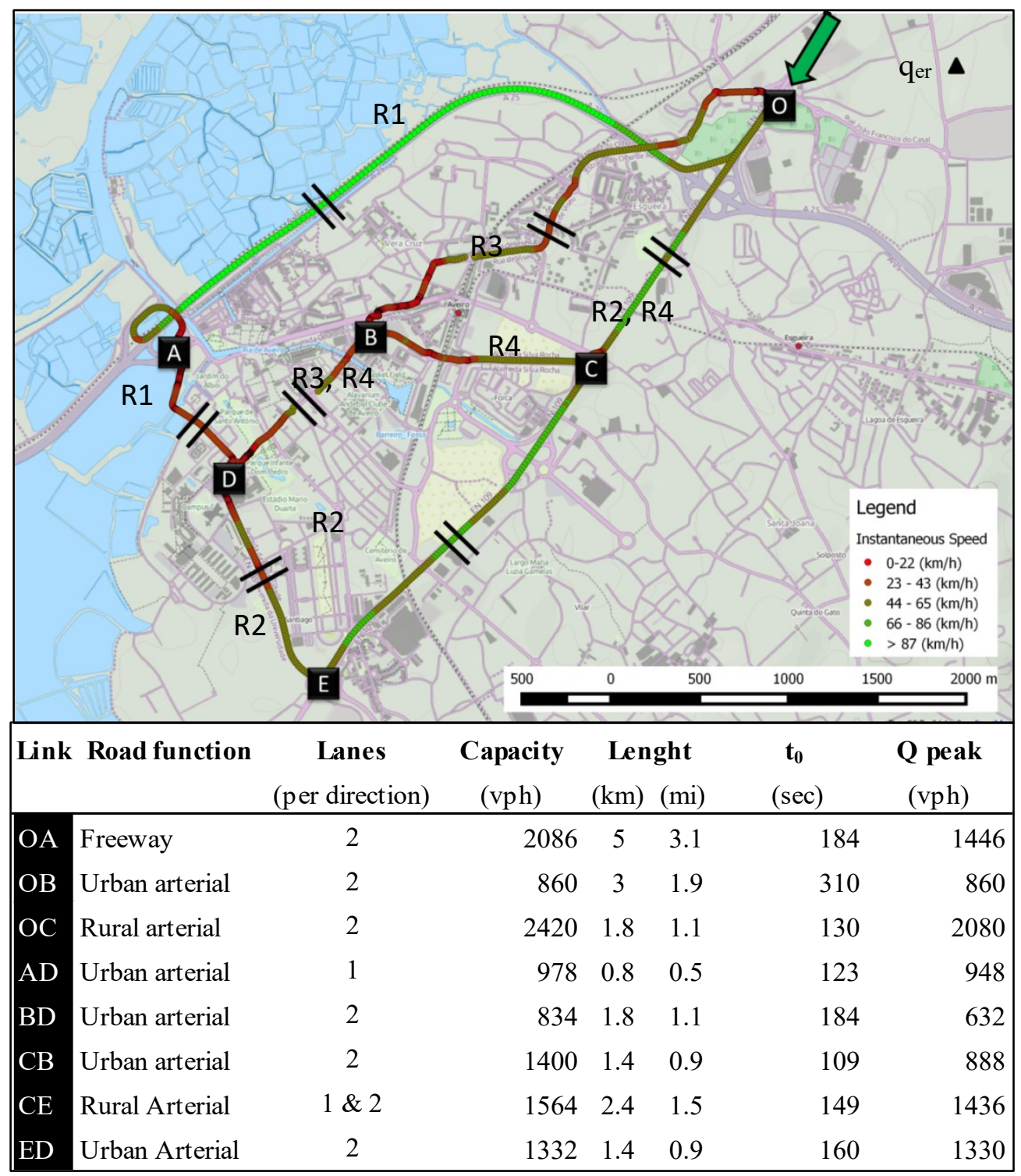

FIGURE 2 Study network map (Open Street Maps Background) with GPS speed data gathered on a representative commuting day. Link parameters: Road function, number of lanes, capacity, length, free flow time $\left(t_{0}\right)$, average flow at peak hour ( $Q$ peak) 


\subsubsection{Field data collection}

To evaluate the ability of the traffic model in generating realistic speed profiles, second-bysecond vehicle dynamics data from Light Duty Vehicles (LDV) equipped with a GNSS device recorder was used. A pre-existing empirical data set including approximately $550 \mathrm{~km}$ of GNSS data over 15 hours was considered (Bandeira et al., 2016). Vehicle dynamics were compared along ten road segments with heterogeneous traffic conditions across the study domain including urban, arterial and freeway roads. GNSS data was recorded in the main roads of the city including all routes studied in this paper.

Approximately 15 trips for each road segment during the peak hour (8.15-9.15 a.m.) were identified and extracted for this procedure. To reduce systematic errors, 5 drivers with varying levels of driving experience performed the same number of trips for each route. In addition, traffic volumes were monitored throughout video cameras in 14 strategic points of the study network. Based on these data, time dependent and turning movements counts were defined for each main intersection.

\subsection{Traffic and emissions simulation}

\subsubsection{Integrated platform - simulation tools}

A traffic-emission micro simulation platform (Fontes et al., 2014) integrating the microscopic traffic simulator PTV VISSIM (PTV, 2005) and the instantaneous emission modelling approach based on vehicle specific power (VSP) (EPA, 2002) was used. Although this platform has been run specifically for this study, part of the calibration and validation work of the model parameters was done and presented in previous work of the research team (Fontes et al., 2014). VISSIM microscopic model was chosen because it allows carrying out a detailed analysis of traffic performance over different links according to different levels of 
demand. This modelling structure allows computing vehicles dynamics (speed, acceleration and grade) at $1 \mathrm{~Hz}$ rate. In the simulation period, 15,00o vehicles are assigned to the whole city network.

Emissions are estimated based on VSP which represents the sum of the loads resulting from aerodynamic drag, acceleration, rolling resistance, and road grade, all divided by the mass of the vehicle (Palacios, 1999). This platform considers VSP values categorized in 14 modes without further division in speed ranges (such as it is considered in MOVES). This approach was selected to facilitate the process of calibration and validation of VSP distribution modes generated by VISSIM. Furthermore, it has been shown that there was not a significant difference in emission rates predicted on a driving cycle average basis (EPA, 2002). Modes 1 and 2 represents deceleration modes (negative VSP values), VSP 3 includes the idle mode (VSP O). VSP modes 4 to 14 represent combinations of positive accelerations and growing speeds. The VSP function, modal range values and respective emissions factors, as well as detailed explanations of the emission estimation are available in numerous publications (Bandeira et al, 2013; Fontes et al., 2014. Frey, Zhang, \& Rouphail, 2008b).

\subsubsection{Calibration and Validation}

The traffic modeling platform was evaluated using the field data collected from the study domain. This task was made in two phases: calibration and validation. Traffic model was calibrated by addressing the effect of vehicle performance, driver behaviour and simulation resolution parameters on traffic flows in the 14 points of the study domain where data were collected. The main traffic model parameters were the car-following (average standstill distance, additive and multiple part of safety distance), lane-change and gap acceptance (front gap, rear gap, safety factor, anticipate route), and simulation resolution (Fontes et al., 2014; Borrego et al.; 2016).

Model validation seeks to evaluate how well the estimated parameters match the observed data using 10 random seed runs (Hale, 1997). The following parameters were validated: 1 ) 
traffic flow; 2) travel time; 3) average speed; 4) Vehicle Specific Power (VSP) cumulative modes distributions; and 5) $\mathrm{NO}_{\mathrm{x}}, \mathrm{CO}, \mathrm{HC}$ and $\mathrm{CO}_{2}$. It should be mentioned that, in this case, emissions were estimated through empirical VSP distribution (they were not directed measured in the field).

The widely-accepted Geoffrey E. Havers (GEH) and the Root-Mean-Square Error (RMSE) goodness of fit measures were used to compare observed and estimated traffic flows. In order to meet the validation criteria, GEH values should be less than 4 for at least $85 \%$ of the links (Dowling, Skabadonis, \& Alexiadis, 2004).

Also, the observed and estimated VSP cumulative modes distributions were calculated from travel time data for each route performed and VISSIM traffic model, respectively, and further compared using the two-sample Kolmogorov-Smirnov (K-S) test. Because of the good correlation between VSP modes and acceleration-deceleration distributions, this step is suitable to analyse the accuracy of the modeling tool (Hongyu, Guohua, \& Lei, 2016). For more detail about this validation procedure can be found elsewhere (Fontes et al., 2014).

\subsubsection{Road segment-based emissions}

Total emissions per main road segment were calculated considering $45 \%$ of light duty gasoline vehicles (LDGV), $35 \%$ of light duty diesel vehicles (LDDV) and $20 \%$ of light commercial diesel vehicles (LCDV) (ACAP, 2012). The platform includes a C\# code to compute the second-by-second data (speed, acceleration/deceleration generated in the VISSIM. Each of these values associated to a link and road segment ( $s$ ) were processed and then the distribution VSP modes frequency was calculated $\left(n_{s, V S P}\right)$. Lastly, $\mathrm{NO}_{\mathrm{x}}, \mathrm{CO}, \mathrm{HC}$, and $\mathrm{CO}_{2}$ emissions by road segment were derived based on the time spent $\left(n_{V S P, i}\right)$ in each VSP mode $i$ (seconds), for the total number of vehicles using the road segment $s(Q)$, multiplied by its respective emission factor $\left(e_{p}\right)$ (see Eq. 1 and 2).

$$
\begin{array}{ll}
\boldsymbol{n}_{\boldsymbol{S V S P}_{\boldsymbol{i}}}=\sum_{j}^{Q} \sum_{\boldsymbol{i}}^{\mathbf{1 4}}\left(\boldsymbol{V S S P}_{\boldsymbol{i}}\right) & \text { Eq. (1) } \\
P_{S}=\sum_{i=1}^{14} n_{V S P_{i}}\left\{\left(x \times e_{P, i}\right)_{L D G V}+\left(x \times e_{P, i}\right)_{L D D V}+\left(x \times e_{p, i}\right)_{L C D V}\right\} & \text { Eq. (2) }
\end{array}
$$


Where:

nSVSP,i - time (seconds) spent on mode VSP mode $i$ (1 to 14) for the total flow $Q$ of vehicles $(j)$ using a road segment $s$ for a given period of time;

$P_{s}-$ Total emissions (g) by pollutant $p\left(\mathrm{NO}_{\mathrm{x}}, \mathrm{CO}, \mathrm{HC}\right.$, and $\left.\mathrm{CO}_{2}\right)$ generated on the road segment $\mathrm{s}$ for a given period of time; for the total flow $Q$ of vehicles $(j)$ using the road segment $s$ for a given period of time;

$x$ - Share of vehicle types (\%) in the fleet;

$e_{p}-$ Emissions factor (g.sec ${ }^{-1}$ ) of pollutant $p$ for VSP mode $i$ according to the vehicle type.

To overcome the potential problem of environmental contradictory objectives in optimizing routes (Levin et al., 2014), a method to weigh the cost of each pollutant was used. The monetary values applied (2012 USD per gram) were: $\mathrm{NO}_{\mathrm{X}}$ - 0.0248; CO - 0.00416; $\mathrm{HC}$ 0.008271; and $\mathrm{CO}_{2}-0.00007$, suggested in a recent AERIS project report (US DOT, 2012). These values should be adjusted to the local context as soon as more accurate information about the costs of these pollutants is available and updated. Henceforth, the results of this weighing process will be denominated environmental damage (ED) costs.

\subsection{Development of Volume-Delay-Functions and Volume-Emissions-Functions}

The performance analysis of different routing strategies is based in terms of travel time TT), $\mathrm{CO}_{2}$ (global pollutant and directly related to fuel use), $\mathrm{NO}_{\mathrm{X}}$ (a key precursor to troposphere ambient ozone) and overall environmental damage costs. Therefore, Volume-DelayFunctions (VDF), Volume-Emissions-Functions (VEF) and Volume-EnvironmentalDamage-Functions (VEDF) for each main road segment were defined. This procedure aimed at developing a library of accurate relationships which can be matched with traffic data from road sensors in real-time and then be straightforwardly applied in the traffic flow optimization. 
These proposed functions use the traffic volume as an independent variable and travel time (VDF), emissions (VEF), and environmental damage costs (VEDF) as dependent variables. VDF were used to conjecture the equilibrium conditions on the network in terms of travel time. VEF and VEDF were applied to optimize the flow distribution of eco-routing vehicles among the alternative routes and under environmental objectives. For developing VEF and VEDF the subsequent steps were followed and applied over each main road segment:

1) Removal of all vehicles in the simulated network whose OD pair is similar to the case study;

2) Simulation of progressive increments in demand (20 vph) until the road segment capacity is reached [10 runs random seed (Hale, 1997)] over each main road segment;

3) Estimation of road segment emissions from equation 2, during the simulation time interval;

4) Assessment and plot of average emissions/ environmental damage costs emitted by a representative vehicle of the local fleet over different levels of demand;

5) Regression analysis to determine the most appropriate performance function of the road-segment based.

The first step reflects the study's assumption that vehicles using the links under study with other destinations keep the same behavior. Therefore, driving cycles and link performance functions are developed considering minimum demand levels and reflecting vehicle interactions with traffic from adjacent links and/or with different OD pairs. The second step concerning the simulation of progressive increments in demand (20 vph) is a compromise between the need to develop consistent correlation models and the time required to run the 10 random seeds recommended in the literature (Hale, 1997). The following steps correspond to the calculation of total emissions for various levels of demand (3) and the development of environmental performance models (ED costs, $\mathrm{NO}_{\mathrm{x}}$ and $\mathrm{CO}_{2}$ ) for a representative vehicle as function of demand $Q$ (4 and 5).

After conducting multiple regression analysis, a cubic polynomial function was shown to be appropriated to interpolate traffic volume with total $\mathrm{ED}$ costs, $\mathrm{NO}_{\mathrm{x}}$ and $\mathrm{CO}_{2}$ emissions over the eight segments investigated. Table 2 summarizes the regression coefficients and 
statistics for the whole set of road segment performance functions. The Anova significance F value shows the probability that the regression does not explain the variation in emissions or environmental damage, i.e. that any fit is purely by chance.

Table 2 Regression coefficients and regression statistics for VEF and VEDF

\begin{tabular}{|c|c|c|c|c|c|c|c|c|}
\hline \multirow[b]{2}{*}{$\mathbf{S}$} & \multirow[b]{2}{*}{ Parameter } & \multirow[b]{2}{*}{ b } & \multicolumn{2}{|c|}{ Regression Coefficients } & \multirow[b]{2}{*}{ q3 } & \multicolumn{2}{|c|}{ Regression Statistics } & \multirow{2}{*}{$\begin{array}{l}\text { ANOVA } \\
\text { Significance } F \\
\end{array}$} \\
\hline & & & $\mathbf{q}$ & q2 & & Multiple R & Standard Error & \\
\hline \multirow[t]{5}{*}{ OA } & NOX (g) & $-1.065 E+03$ & $6.625 \mathrm{E}+00$ & $-5.809 \mathrm{E}-03$ & 3.0587E-06 & 0.99 & 8.842 & $3.905 \mathrm{E}-24$ \\
\hline & $\mathrm{CO}(\mathrm{g})$ & $-1.118 \mathrm{E}+03$ & $6.579 E+00$ & $-6.188 \mathrm{E}-03$ & 3.1950E-06 & 0.99 & 8.990 & $2.457 \mathrm{E}-23$ \\
\hline & $\mathrm{HC}(\mathrm{g})$ & $-9.932 E+01$ & $6.158 \mathrm{E}-01$ & $-7.253 \mathrm{E}-04$ & 4.0135E-07 & 0.99 & 1.642 & $1.968 \mathrm{E}-18$ \\
\hline & $\mathrm{CO} 2(\mathrm{~g})$ & $-3.358 \mathrm{E}+05$ & $2.169 \mathrm{E}+03$ & $-1.867 \mathrm{E}+00$ & $9.9911 \mathrm{E}-04$ & 0.99 & 2953.075 & $2.860 \mathrm{E}-24$ \\
\hline & ED (USD) & $-8.266 \mathrm{E}+01$ & 5.150E-01 & $-4.529 \mathrm{E}-04$ & $2.3876 \mathrm{E}-07$ & 0.99 & 0.682 & $3.624 \mathrm{E}-24$ \\
\hline \multirow[t]{5}{*}{ OB } & NOX (g) & $2.699 \mathrm{E}+04$ & $-1.893 \mathrm{E}+02$ & 4.473E-01 & $-3.4369 \mathrm{E}-04$ & 0.99 & 5.666 & $3.430 \mathrm{E}-03$ \\
\hline & $\mathrm{CO}(\mathrm{g})$ & $3.884 \mathrm{E}+04$ & $-2.828 \mathrm{E}+02$ & 6.919E-01 & $-5.5719 \mathrm{E}-04$ & 0.99 & 2.962 & $1.279 \mathrm{E}-03$ \\
\hline & $\mathrm{HC}(\mathrm{g})$ & $4.771 \mathrm{E}+03$ & $-2.729 E+01$ & 4.735E-02 & $-1.9694 \mathrm{E}-05$ & 0.99 & 4.391 & $1.511 \mathrm{E}-02$ \\
\hline & $\mathrm{CO}$ (g) & $7.873 E+06$ & $-5.389 E+04$ & $1.245 \mathrm{E}+02$ & $-9.2432 \mathrm{E}-02$ & 0.99 & 2378.141 & $4.136 \mathrm{E}-03$ \\
\hline & ED (USD) & $1.905 E+03$ & $-1.320 E+01$ & 3.083E-02 & $-2.3298 \mathrm{E}-05$ & 0.99 & 0.487 & $3.898 \mathrm{E}-03$ \\
\hline \multirow[t]{5}{*}{ OC } & NOX (g) & $6.136 E+01$ & 5.167E-01 & $3.081 \mathrm{E}-04$ & $-6.1625 \mathrm{E}-08$ & 0.99 & 2.143 & $1.631 \mathrm{E}-10$ \\
\hline & $\mathrm{CO}(\mathrm{g})$ & $1.293 E+02$ & $2.313 \mathrm{E}-01$ & 4.493E-04 & $-1.0816 \mathrm{E}-07$ & 0.99 & 1.537 & $7.318 \mathrm{E}-11$ \\
\hline & $\mathrm{HC}(\mathrm{g})$ & $-4.648 \mathrm{E}+01$ & $2.520 \mathrm{E}-01$ & $-2.064 \mathrm{E}-04$ & $9.2980 \mathrm{E}-08$ & 0.99 & 0.580 & $8.056 \mathrm{E}-09$ \\
\hline & CO2 (g) & $-4.024 \mathrm{E}+02$ & $2.630 E+02$ & 3.567E-02 & $8.7430 \mathrm{E}-06$ & 0.99 & 912.704 & $2.866 \mathrm{E}-10$ \\
\hline & ED (USD) & $1.189 E+00$ & $5.205 \mathrm{E}-02$ & 1.100E-05 & $5.0280 \mathrm{E}-10$ & 0.99 & 0.176 & $1.870 \mathrm{E}-10$ \\
\hline \multirow[t]{5}{*}{ AD } & NOX (g) & $8.002 \mathrm{E}+02$ & $-1.291 \mathrm{E}+00$ & $-8.158 \mathrm{E}-03$ & $1.9331 \mathrm{E}-05$ & 0.95 & 38.464 & 1.069E-04 \\
\hline & $\mathrm{CO}(\mathrm{g})$ & $-3.550 E+02$ & $5.084 E+00$ & $-1.750 \mathrm{E}-02$ & $2.0752 \mathrm{E}-05$ & 0.95 & 19.390 & $1.523 \mathrm{E}-05$ \\
\hline & $\mathrm{HC}(\mathrm{g})$ & $1.642 \mathrm{E}+03$ & $-8.666 E+00$ & $1.154 \mathrm{E}-02$ & $5.9620 \mathrm{E}-07$ & 0.88 & 30.045 & $4.531 \mathrm{E}-04$ \\
\hline & CO2 (g) & $2.974 E+05$ & $-2.427 E+02$ & $-4.282 E+00$ & $8.8920 \mathrm{E}-03$ & 0.92 & 16119.909 & 1.100E-04 \\
\hline & ED (USD) & $6.451 \mathrm{E}+01$ & $-9.760 \mathrm{E}-02$ & $-6.927 \mathrm{E}-04$ & $1.6077 \mathrm{E}-06$ & 0.96 & 3.133 & $1.004 \mathrm{E}-04$ \\
\hline \multirow[t]{5}{*}{ BD } & NOX (g) & $-3.356 \mathrm{E}+03$ & $3.366 \mathrm{E}+01$ & $-1.099 \mathrm{E}-01$ & 1.2624E-04 & 0.99 & 27.292 & 5.175E-06 \\
\hline & $\mathrm{CO}(\mathrm{g})$ & $-2.078 \mathrm{E}+03$ & $2.099 \mathrm{E}+01$ & $-6.755 E-02$ & 7.6905E-05 & 0.99 & 15.998 & $3.292 \mathrm{E}-06$ \\
\hline & $\mathrm{HC}(\mathrm{g})$ & $-2.342 \mathrm{E}+03$ & $2.331 \mathrm{E}+01$ & $-7.729 \mathrm{E}-02$ & $8.9260 \mathrm{E}-05$ & 0.99 & 19.062 & $8.322 \mathrm{E}-06$ \\
\hline & $\mathrm{CO} 2$ (g) & $-1.305 E+06$ & $1.305 E+04$ & $-4.248 \mathrm{E}+01$ & 4.8715E-02 & 0.99 & 10589.905 & $4.958 \mathrm{E}-06$ \\
\hline & ED (USD) & $-2.609 \mathrm{E}+02$ & $2.613 E+00$ & $-8.504 \mathrm{E}-03$ & $9.7662 \mathrm{E}-06$ & 0.99 & 2.130 & 4.581E-06 \\
\hline \multirow[t]{5}{*}{ CB } & NOX (g) & $-2.114 \mathrm{E}+01$ & 7.324E-01 & $-4.245 \mathrm{E}-04$ & 4.6779E-07 & 0.99 & 1.268 & $4.483 \mathrm{E}-26$ \\
\hline & $\mathrm{CO}(\mathrm{g})$ & $-1.906 \mathrm{E}+01$ & 6.647E-01 & $-4.479 \mathrm{E}-04$ & 4.8831E-07 & 0.99 & 1.264 & $2.096 \mathrm{E}-25$ \\
\hline & $\mathrm{HC}(\mathrm{g})$ & $-1.232 \mathrm{E}+01$ & $1.999 \mathrm{E}-01$ & $-2.473 \mathrm{E}-04$ & 2.7244E-07 & 0.99 & 0.601 & $3.721 E-22$ \\
\hline & $\mathrm{CO} 2(\mathrm{~g})$ & $-1.111 \mathrm{E}+04$ & $3.091 E+02$ & $-2.016 \mathrm{E}-01$ & 2.1902E-04 & 0.99 & 535.329 & 5.979E-26 \\
\hline & ED (USD) & & & & & & 0.104 & $3.132 E-26$ \\
\hline \multirow[t]{5}{*}{ CE } & NOX (g) & $-4.856 \mathrm{E}+02$ & $3.978 \mathrm{E}+00$ & $-7.339 E-03$ & 5.4507E-06 & 0.99 & 21.074 & $8.685 \mathrm{E}-06$ \\
\hline & $\mathrm{CO}(\mathrm{g})$ & $-4.173 E+02$ & $3.402 E+00$ & $-6.433 E-03$ & 4.8241E-06 & 0.99 & 5.552 & $1.124 \mathrm{E}-05$ \\
\hline & $\mathrm{HC}(\mathrm{g})$ & $-1.201 \mathrm{E}+02$ & $9.648 \mathrm{E}-01$ & $-1.969 \mathrm{E}-03$ & $1.4491 \mathrm{E}-06$ & 0.99 & 1.797 & 4.211E-05 \\
\hline & $\mathrm{CO}$ (g) & $-1.677 \mathrm{E}+05$ & $1.396 \mathrm{E}+03$ & $-2.493 E+00$ & $1.8506 \mathrm{E}-03$ & 0.99 & 8102.070 & 5.267E-06 \\
\hline & ED (USD) & & & & & 0.99 & 1.698 & 5.151E-06 \\
\hline \multirow[t]{5}{*}{ ED } & NOX (g) & $-5.519 E+03$ & $3.015 E+01$ & $-5.206 \mathrm{E}-02$ & $3.0851 \mathrm{E}-05$ & 0.99 & 3.631 & $8.288 \mathrm{E}-06$ \\
\hline & $\mathrm{CO}(\mathrm{g})$ & $-4.369 E+03$ & $2.394 E+01$ & $-4.129 \mathrm{E}-02$ & $2.4555 \mathrm{E}-05$ & 0.99 & 2.976 & $5.689 \mathrm{E}-06$ \\
\hline & $\mathrm{HC}(\mathrm{g})$ & $-3.686 \mathrm{E}+03$ & $1.985 E+01$ & $-3.492 \mathrm{E}-02$ & $2.0645 \mathrm{E}-05$ & 0.99 & 2.176 & $1.763 \mathrm{E}-04$ \\
\hline & $\mathrm{CO} 2(\mathrm{~g})$ & $-2.001 E+06$ & $1.098 \mathrm{E}+04$ & $-1.893 \mathrm{E}+01$ & $1.1232 \mathrm{E}-02$ & 0.99 & 1368.042 & $7.261 \mathrm{E}-06$ \\
\hline & ED (USD) & $-4.463 E+02$ & $2.443 E+00$ & $-4.218 \mathrm{E}-03$ & $2.5007 \mathrm{E}-06$ & 0.99 & 0.288 & $7.208 \mathrm{E}-06$ \\
\hline
\end{tabular}


Figure 3 exemplifies the shapes of VEDF and VDF for the set of road segment analyzed. As may be seen VEF may be not monotonically increasing. Depending on the characteristics of each road segment, recurrently an increase in volume and its consequent reduction of higher speeds frequency may lead to a decrease in emissions. It may also be noticed that some road segments are more sensitive to increased demand. For instance, from a certain level of demand, the waiting time at intersections with traffic lights is higher because the traffic flow is not processed in a single cycle.
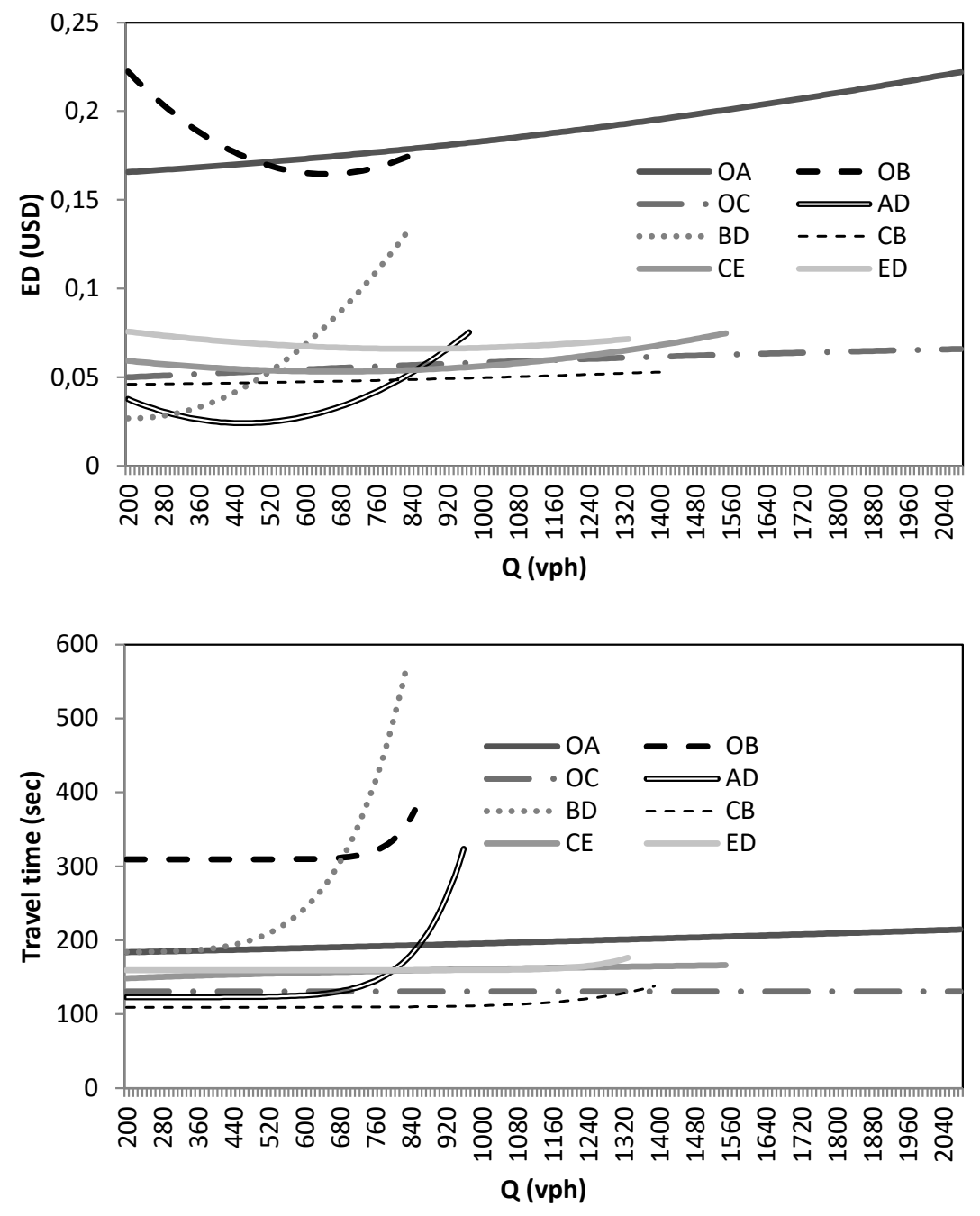

Figure 3 Estimated VdmF (top) and VDF (bottom) for the set of links analyzed. 
Unlike emissions, travel time functions are monotonically increasing. For VDF the widely used Bureau of Public Roads (BPR) functions (Bureau of Public Roads, 1964) were applied. BPR function ensures convexity of the congestion function which is not a necessary, but a desirable property (Spiess, 1990). The equation parameters ( $\alpha$ and $\beta$ ) were optimized to get a deeper insight of each road segment performance. An optimal combination of $\alpha$ and $\beta$ parameters was conducted to each road segment in order to minimize the Root Mean Square Error (RMSE). Despite some inherent known drawbacks mentioned in literature (e.g. Spiess, 1990), taking into account the volume to capacity ratio (V/C) range analyzed, this BPR approach has shown consistent results.

\subsection{Description of evaluated Scenarios}

In addition to the baseline scenario, four scenarios were assessed including two levels of ecorouting vehicles (750 and $1500 \mathrm{vph}$, which corresponds to approximately $50 \%$ and $100 \%$ of the total traffic for this $\mathrm{O} / \mathrm{D}$ pair) and two levels of network saturation $(\mathrm{V} / \mathrm{C}$ of $50 \%$ and $80 \%$ ). These values reflect realistic values of congestion levels over the year in the city at rush hour.

- A - Saturation 50\% - Intermediate level (IL) of Eco-routing acceptance - 750 vph;

- B - Saturation 50\% - High level (HL) of eco-routing acceptance - $1500 \mathrm{vph}$;

- C - Saturation 80\% - Intermediate level (IL) of Eco-routing acceptance - $750 \mathrm{vph}$;

- D - Saturation 80\% - High level (HL) of Eco-routing acceptance - 1500 vph.

For intermediate levels (IL) of eco-routing, acceptance (scenarios A and C) three sub scenarios related to the distribution of demand of these vehicles have been considered:

- A and C - Stochastic distribution of eco-routing vehicles considering the average of impacts resulting from 10 random binary matrices of eco-routing (1) and not ecorouting vehicles (O) e.g. $(1,0,1,1 \ldots .1,01),(1,00, \ldots 1,1,0)$ 
- A1 and c1 Considering the extreme scenario in which the whole population of ecorouting vehicles ( 1 ) is assigned at the beginning $(1,1,1,1 \ldots 0,0,0)$ of the incremental assignment procedure.

- A2 and C2 Considering the extreme scenario in which the whole population of non eco-routing vehicles $(0)$ is assigned at the beginning $(0,0,0, . .1,1,1)$ of the incremental assignment procedure.

The first set of sub scenarios (A and C) simulate a more realist approach based on a stochastic demand of the two groups of drivers. Sub scenarios 1 and 2 allow to predict the maximum magnitude of impacts according to the demand distribution order of eco-routing (1) and non-eco-routing vehicles (o).

\subsection{Traffic flow optimization}

Two routes guidance procedures for traffic flow optimization were tested: 1) minimize the individual impacts of each eco-routing vehicle $j$ approaching the network (UE scenarios); and 2) minimize the overall impacts of the network based on an optimization of the flow patterns. Both assignment strategies were explored independently in a current spreadsheetbased format.

For traffic assignment under UE, an iterative process based on the Wardrop's first principle was followed i.e., for each iteration a single minimum travel time/pollution route was calculated based on road segment parameters for the corresponding departure time. This is a seemly method to represent strategies which does not provide estimates of future traffic conditions (Levin et al., 2014). Thus, according to the purpose of each traffic assignment scenario, VDF (travel time), VEF (emissions) and VEDF (Environmental Damage Cost) were used to determine which route enables the minimization of individual impacts of each ecodriver approaching the network.

The traffic assignment under UE method is performed according to the following procedure.

For $j=1$ to 1500 


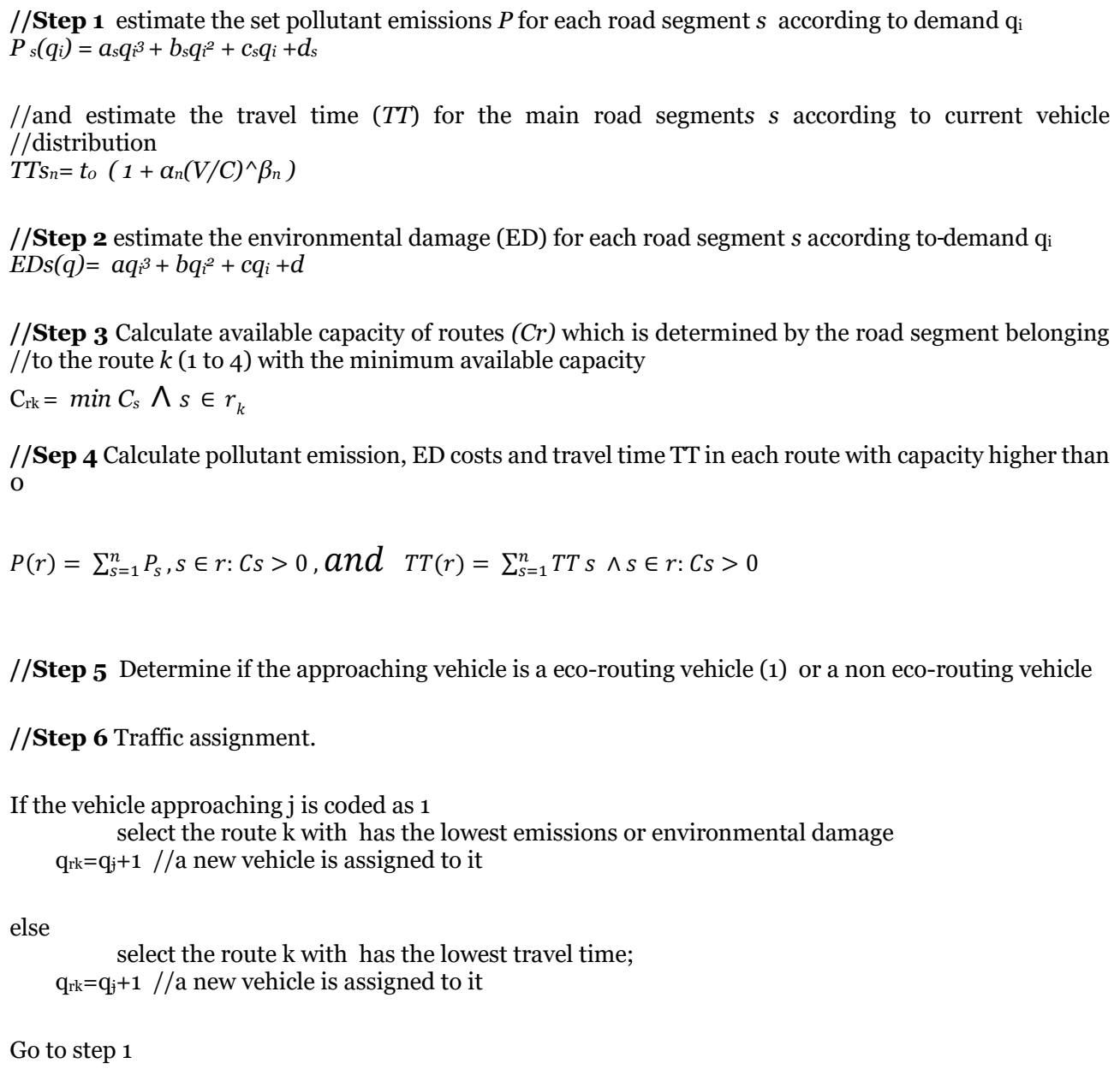

System optimum (SO) procedures are based on the assumption that drivers are routed to minimize system pollution $\left(\mathrm{S}_{\mathrm{P}}\right)$ or system travel time $\left(\mathrm{S}_{\mathrm{TT}}\right)$.

The minimization of a given pollutant $P$ over the whole system $\left(\mathrm{S}_{\mathrm{P}}\right)$ is achieved by assigning eco-routers $\left(q_{e r}\right)$ on the network in such a way that the sum of total pollutant costs caused by eco-routing vehicles and non-eco-routing vehicles $\left(q+q_{e r}\right)$ in all road segments $(S)$ of the network is minimized (Eq. 3). The conventional constraints ensure that the maximum capacity on each road segment is not reached (Eq. 4), the non-negativity of traffic flow (Eq. 5) and conservation of eco-routers flow in each node (Eq. 6). 
Minimize $f S P\left(q_{e r}\right)=\sum_{l}^{L} P_{S}$

Eq. (3)

Subject to:

$q_{e r}+q \leq C_{s} \wedge s \in r$

Eq. (4)

$q_{e r}, s \geq 0$

Eq. (5)

For a set of nodes N:

$$
\sum_{\text {into } N} q_{e r}=\sum_{\text {out of } N} q_{e r}
$$

Where:

$$
\begin{aligned}
& \mathrm{q}_{\mathrm{er}} \text { - Traffic flow (vph) of eco-routing vehicles; } \\
& \mathrm{q} \text { - General traffic flow (vph); } \\
& \mathrm{C}_{\mathrm{l}} \text { - Estimated maximum capacity (vph) for the road segments }
\end{aligned}
$$

Despite the simplicity of the network, this problem is non-linear and non-convex due to the nature of the polynomial functions. In line with previous research with analogous objectives (Ferguson, Duthie, \& Travis Waller, 2012; Karoonsoontawong \& Waller, 2006), an evolutionary algorithm (EA) was chosen to solve the problem. After conducting a sensitive analysis, the mutation rate was set at 0.01 , and the population was set at 100 . The optimization was performed by applying Premium Solver Platform which is add on in the Excel MSOffice environment The number of iterations was set such that the objective function was no longer improving in each scenario. In future, this process could be accelerated, for example, by applying machine learning algorithms to learn the best flow distributions according to demand. 


\section{RESULTS}

First, the model evaluation is briefly summarized (see Section 3.1). Them, different equilibrium flow distributions are presented (see Section 3.2). Finally, an overall evaluation of different route guidance strategies on network performance, emissions and ED costs is provided (see Section 3.3).

\subsection{Evaluation of the Integrated Model platform}

The distribution of VSP modes generated by the traffic model is a key factor for assessing its capacity to properly simulating the microscopic driving cycle patterns required for the instantaneous emission model. Figure 4 shows the observed and estimated cumulative discrete distributions of VSP modes for each analyzed road segment. 

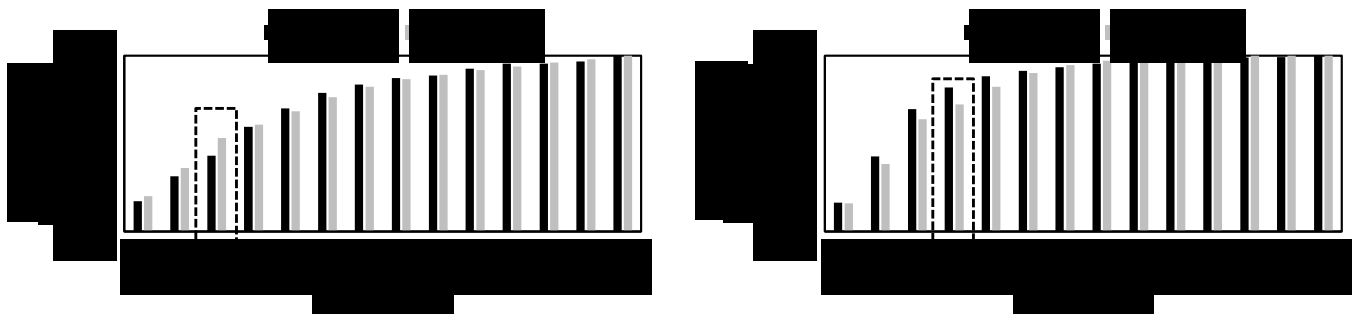

Road segment 3 - Suburban/urban

Road segment 4 - Urban
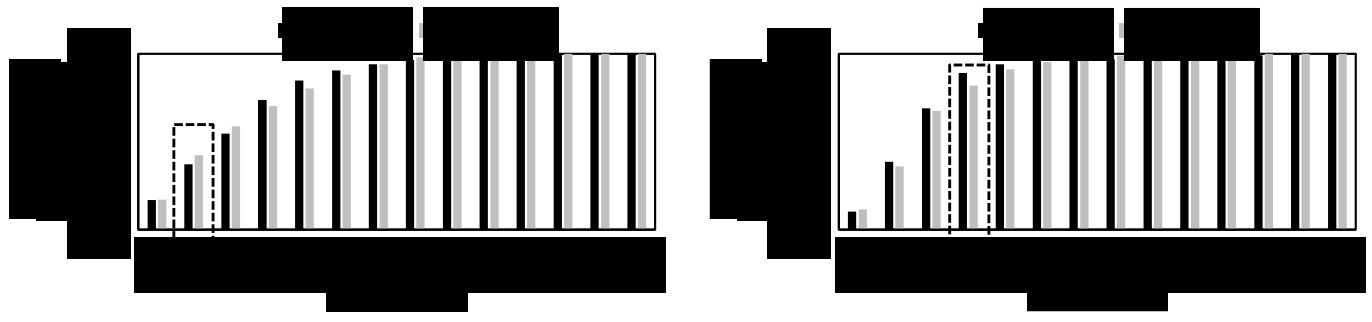

Road segment 5 - Urban

Road segment 6 - Suburban/urban
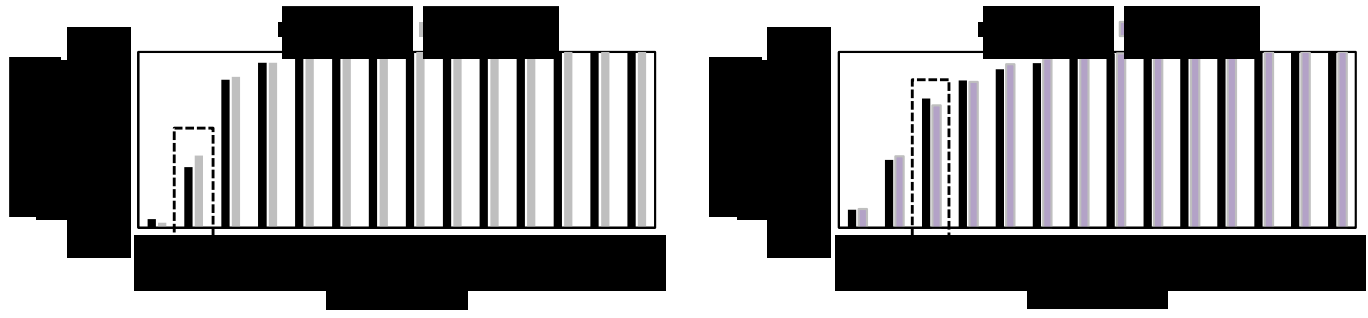

Road segment 7 - Urban

Road segment 8 - Suburban/urban
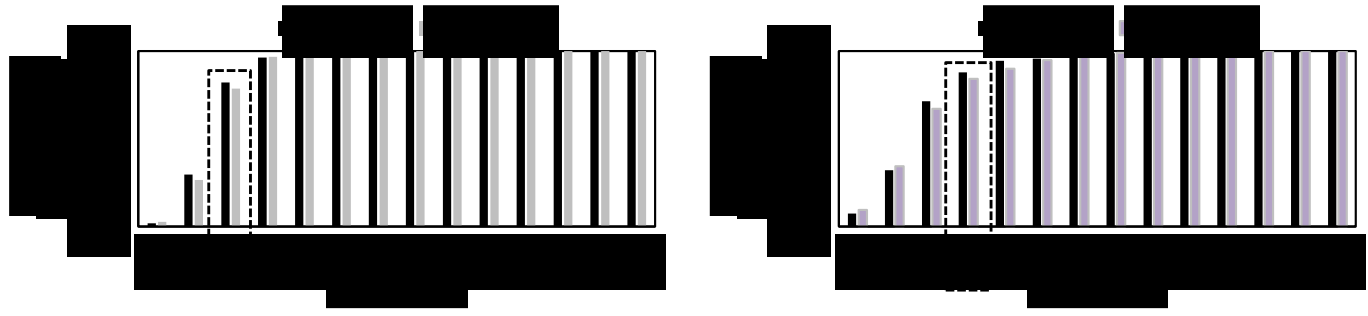

Road segment 9 - Freeway

Road segment 10 - Urban

Figure 4 Observed versus estimated VSP modes in terms of cumulative distributions for each road segment performed. 
The same trend is observed clearly for these VSP modes distributions (i.e., every route achieved a $D$-value smaller than $D$-critical at a 95\% confidence level). The highest differences were found for modes 2 and 4 (modes with reduced speeds and decelerations or low accelerations), and mode 3 (mode associated with idling/low speed situations). In route 9, mostly performed in freeway road, the highest difference was found for mode 13. This occurs because simulated vehicles reach the maximum speed $(\approx 120 \mathrm{~km}$ per hour $)$ and tend to drive at constant speed (without acceleration).

Table 1 Evaluation parameters, test and result of the traffic and emissions simulation platform with respect to the validation process (T Fontes et al., 2014).

\begin{tabular}{|c|c|c|}
\hline Evaluated parameter & Test & Result \\
\hline Traffic volume in 14 points of the & GEH & 0.2 to 1.2 \\
\hline network & RMSE & $<10 \%$ \\
\hline Travel time on 10 road sections & GEH & Max. 0.7, Min. 0.1, Av. 0.3 \\
\hline Average speed & GEH & Max. o.6, Min. o.1, Av. 0.2 \\
\hline VSP mode distributions & K-S test & Not significant at $95 \% \mathrm{CI}$ \\
\hline $\mathrm{CO}_{2}$ emissions & $\begin{array}{l}\text { Relative error } \\
\text { (\%) }\end{array}$ & Max. 8.2\%, Min. 0.1\%, Av. 2.7\% \\
\hline CO emissions & $\begin{array}{l}\text { Relative error } \\
\text { (\%) }\end{array}$ & Max. 8.8\%, Min. o.7\%, Av. 3.3\% \\
\hline $\mathrm{NO}_{\mathrm{x}}$ emissions & $\begin{array}{l}\text { Relative error } \\
(\%)\end{array}$ & Max. 8.9\%, Min. 1.3\%, Av. 3.8\% \\
\hline HC emissions & $\begin{array}{l}\text { Relative error } \\
\text { (\%) }\end{array}$ & Max. 8.6\%, Min. o.6\%, Av. 2.8\% \\
\hline
\end{tabular}


A summary of results regarding the validation of traffic and emission model platform is presented in Table 1. To compare travel time, average speeds and VSP modes distribution, 20 vehicles were selected for each route performed with the normal traffic conditions of morning peak hour. All traffic flows points have GEH (Geoffrey E. Havers) and RSME below 5 and $10 \%$, respectively. Concerning travel time and average speeds, the results also indicated a good accuracy between observed and estimated data (GEH $<5$ in all road sections) showing that 10 runs per simulation were adequate (Dowling, Skabadonis, \& Alexiadis, 2004).

Considering the VSP cumulative modes distributions, the two-sample K-S test results showed that observed and estimated VSP modes were from the same continuous distribution; for $95 \%$ confidence interval. The data from Table 1 also show that the maximum relative errors between observed and estimated global $\left(\mathrm{CO}_{2}\right)$ and local $\left(\mathrm{CO}, \mathrm{NO}_{\mathrm{x}}\right.$ and $\left.\mathrm{HC}\right)$ pollutant emissions did not reach $10 \%$. In addition, the difference in means samples between those outputs was not significant at 95\% confidence level ( $p$-value > 0.05). The evaluation results strongly suggest the capability of the modelling platform to evaluate the impacts of different demand levels at the selected links. 

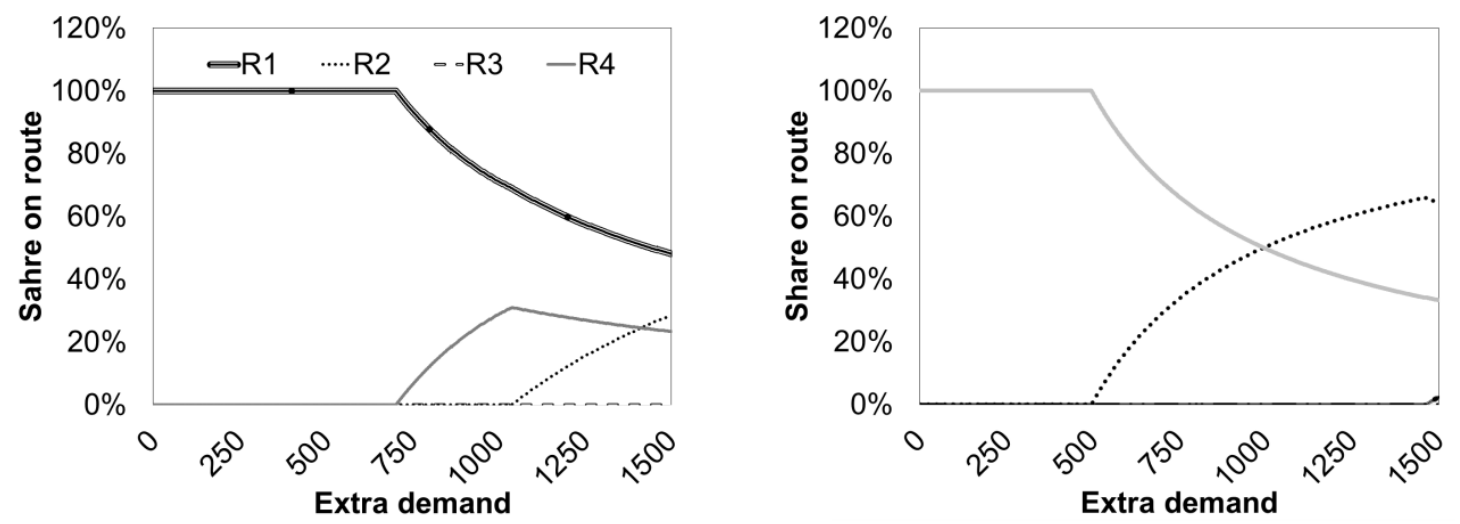

a)

b)

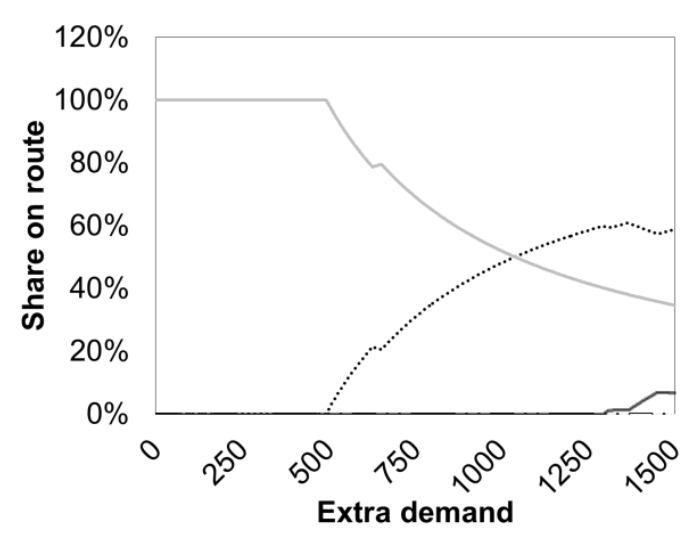

c)

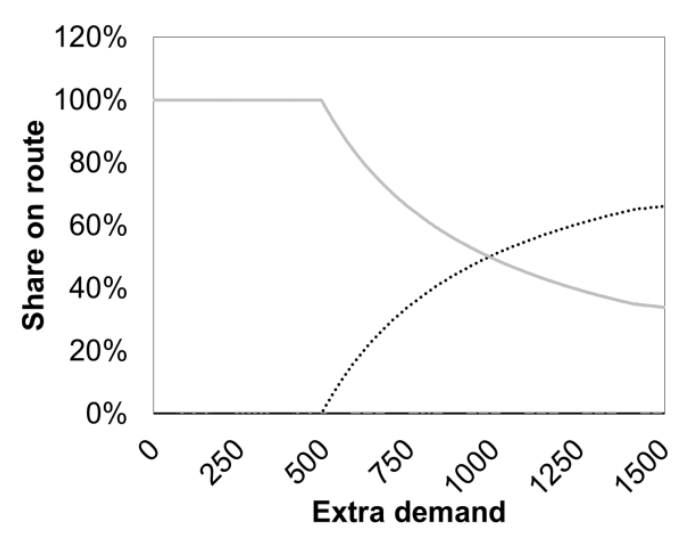

d)

Figure 5 Distribution of equilibrium traffic flow under different criteria: a) travel time; b) $\mathrm{CO}_{2}$ /Fuel consumption; c) $\mathrm{NO}_{\mathrm{x}}$ emissions, d) environmental damage costs.

\subsection{Equilibrium distribution}

In this section, $\mathrm{UE}$ distribution based on travel time ( $\left.\mathrm{UE}_{\mathrm{TT}}\right), \mathrm{CO}_{2} /$ fuel consumption $\left(\mathrm{UE}_{\mathrm{CO}_{2}}\right.$ ), $\mathrm{NO}_{\mathrm{X}}$ emissions ( $\mathrm{UE}_{\mathrm{NO}}$ ), and $\mathrm{ED}$ costs $\left(\mathrm{UE}_{\mathrm{ED}}\right.$ ) is presented. Figure $5 \mathrm{a}$ exemplifies the traffic distribution over the set four routes (R) analyzed considering the travel time as the decision factor for traffic assignment in scenario B that simulates the existence of 1500 eco-routing 
vehicles. If demand is less than $750 \mathrm{vph}$, all vehicles are assigned to the $\mathrm{R} 1$ (motorway route OAD - see Figure 2). When traffic demand exceeds 750 vph, R4 (OCBD) is becoming competitive, and for more than $850 \mathrm{vph}, \mathrm{R} 2$ (OCED) begins to be chosen. At this stage, these routes are in equilibrium with a travel time of 7’30" min. Until $1500 \mathrm{vph}$ Route 3 (OBD) is not used as it entails more travel time that the remaining routes ( $9 \mathrm{~min}$ ).

In Figure $5 \mathrm{~b}$ it is assumed that eco-drivers will choose the route that minimizes their own $\mathrm{CO}_{2}$ emissions. Until a traffic demand of $500 \mathrm{vph}$, route $\mathrm{R} 4$ is the alternative with lowest fuel consumption levels. For a traffic demand higher than $500 \mathrm{vph}$, fuel consumption rises considerably and the arterial route $\mathrm{R} 2$ presents a more competitive alternative. The motorway route $\mathrm{R} 1$ is competitive for demands higher than $1400 \mathrm{vph}$, while $\mathrm{R}_{3}$ is never considered.

Figure $5 \mathrm{c}$ simulates that the most important factor to be minimized is $\mathrm{NO}_{\mathrm{x}}$ emissions. Once more R4 and R2 are in equilibrium after 500 vph and R1 after approximately 1200 vph. Figure $5 \mathrm{~d}$ illustrates the traffic distribution assuming that all incoming eco-routing vehicles are informed of environmental impacts on each route. This integrated approach follows a similar pattern to the routing strategy based on $\mathrm{CO}_{2}$ minimization. In this case, $\mathrm{R} 4$ would be the selected route for all eco-drivers until a demand of approximately $500 \mathrm{vph}$. At this moment, R2 turns into a valid option for eco-routing vehicles. R1 and R3 are not eligible since under the considered demand levels, their ED costs are always higher than the other routes.

\subsection{Assessment of route guidance strategies on network performance, emissions and environmental damage costs}

In this section, the overall impacts in terms of system travel time, system $\mathrm{CO}_{2}$, system $\mathrm{NO}_{\mathrm{x}}$ and SED costs according to different route guidance strategies (SO and UE) with different objectives $\left(\mathrm{CO}_{2}, \mathrm{NO}_{x}, \mathrm{ED}\right)$ are presented. Table 3 shows the overall impacts for both levels of network saturation considering a traditional UE $\mathrm{UT}_{\mathrm{TT}}$ assignment. Thus, assuming that user's 
route choice behavior is primarily affected by travel time, Figure 6 compares each innovative route guidance strategy with the standard flow distribution (UETT) presented in Table3.

Table 3 Network performance (system) and eco-routing vehicles performance (qer) under the standard $\mathrm{UE}_{\mathrm{TT}}$ routing strategy.

\begin{tabular}{|c|c|c|c|}
\hline & Saturation & Low & High \\
\hline \multirow{4}{*}{ Travel time (min) } & qer (per & & \\
\hline & vehicle) & $7 \cdot 47$ & 8.15 \\
\hline & System & & \\
\hline & (per hour) & 8979 & 14228 \\
\hline \multirow{4}{*}{$\mathrm{CO}_{2}(\$)$} & qer (per & & \\
\hline & vehicle) & 0.006 & 0.058 \\
\hline & System & & \\
\hline & (per hour) & 86.8 & 138.5 \\
\hline \multirow{4}{*}{ ED (\$) } & qer (per & & \\
\hline & vehicle) & 0.186 & 0.176 \\
\hline & System & & \\
\hline & (per hour) & 265.5 & 423.6 \\
\hline \multirow{4}{*}{ NOx $_{\mathbf{x}}(\$)$} & qer (per & & \\
\hline & vehicle) & 0.006 & 0.055 \\
\hline & System & & \\
\hline & (per hour) & 82.5 & 131.2 \\
\hline
\end{tabular}



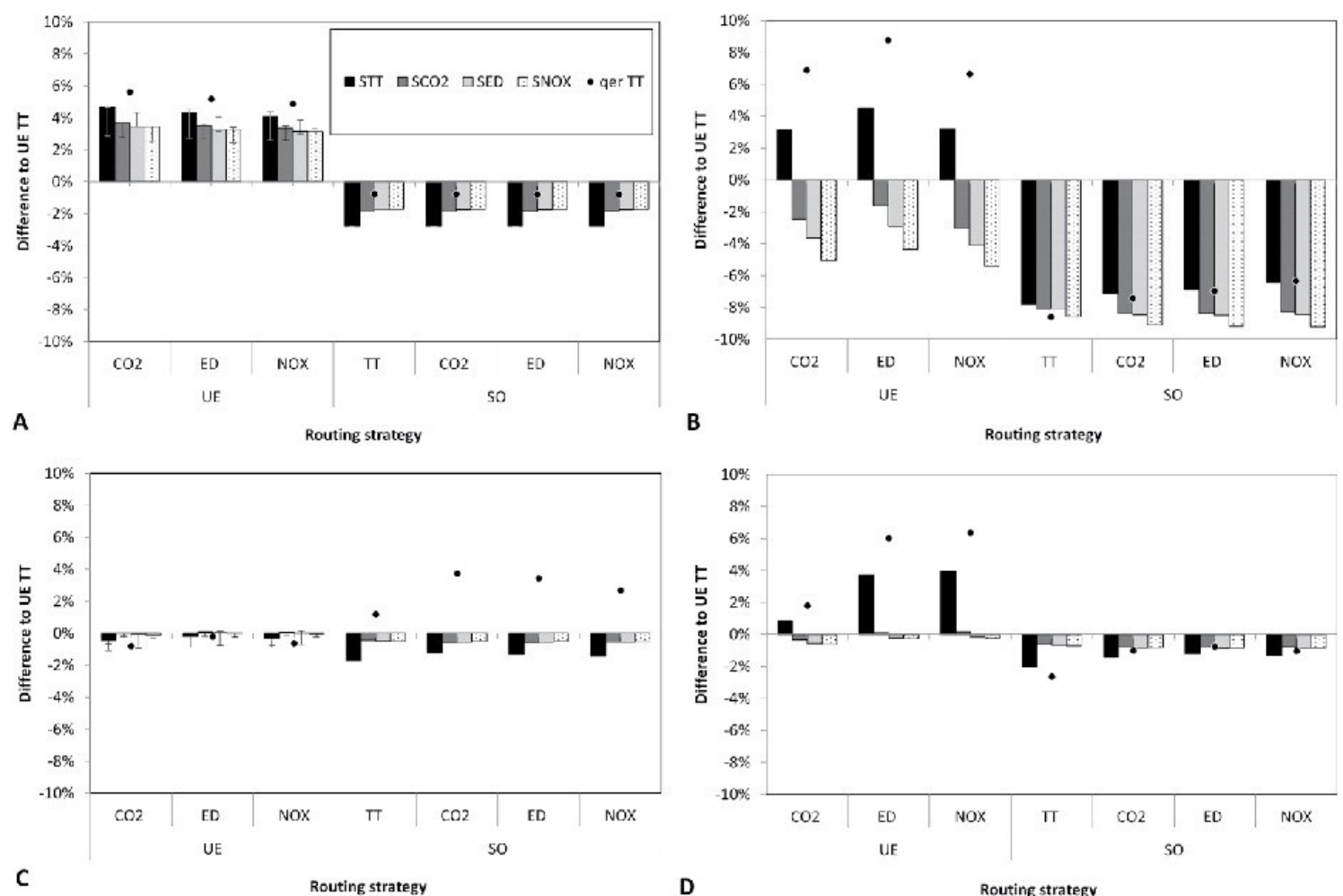

B

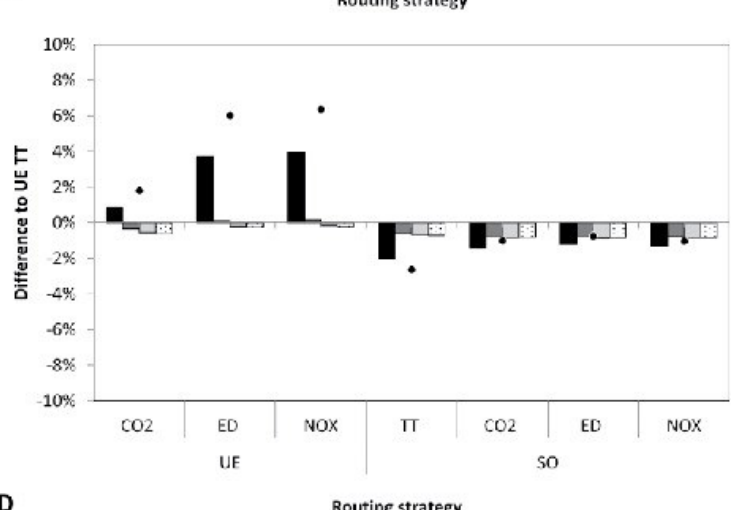

Figure 6 Comparison of performance indicators between innovative routing strategies (UE $\mathrm{CO}_{\mathrm{CO} \text { ED/ NOX }}$; \& SO TT/CO2 ED/ NOX) and standard UE $\mathrm{TT}_{\mathrm{TT}}$ (reference). Relative differences in system emissions and system travel time are represented by bars. Relative differences in the average travel time of ecorouting vehicles are represented by small circles.

In Figure 6 each graph corresponds to the previously defined scenarios (A, B, C and D). The horizontal axis represents each routing strategy. The bars present the relative impact of each routing strategy in terms of System Travel time $\left(\mathrm{S}_{\mathrm{TT}}\right)$, System $\mathrm{CO}_{2}$ emissions $\left(\mathrm{S}_{\mathrm{CO}_{2}}\right)$, System $\mathrm{NO}_{\mathrm{x}}$ emissions $\left(\mathrm{S}_{\mathrm{NOX}}\right)$ and System ED ( $\mathrm{S}_{\mathrm{ED}}$ ) variation (\%) when compared with $\mathrm{UE}_{\mathrm{TT}}$ flow distribution. The small circles represent the relative difference in the average travel time of eco-routing vehicles $\left(\mathrm{q}_{\mathrm{er}}\right)$ in relation to their travel time under $\mathrm{UE}_{\mathrm{TT}}$.

Regarding UE assignment strategies with different environmental criteria it is interesting to 
note that for some conditions of network saturation, a reduction of the emissions impact in the network (up to 5\% - scenario B) can be reached. However, in scenario A, these strategies may have negative impacts on system total emissions. An explanation for this is that when an eco-routing vehicle changes to a specific route, their own improvement is lower than the additional costs inflicted on the other travelers. This situation occurs when vehicles routed under environmental concerns are diverted to R4, significantly affecting the performance of the remaining vehicles traveling in the links crossing the city center.

Interestingly, it also has been found that routing vehicles with different purposes (such as minimizing $\mathrm{CO}_{2}$ emissions and ED) may actually lead to better results in minimizing other parameters (e.g. see ED costs - scenario B). Generally, it seems that the minimization of pollutant emissions under $\mathrm{UE}_{\mathrm{ED} / \mathrm{CO}_{2}}$ assignment implies an increase in travel time of ecorouting vehicles and often in system $\mathrm{S}_{\mathrm{TT}}$. In scenarios $\mathrm{A}$ and $\mathrm{C}$, the error bars in UE routing strategies show the oscillation in environmental impacts for the two extreme sub scenarios of eco-routing vehicles demand distribution - A1,C1 and A2,C2. The variability of system affects according to the distribution pattern of eco-routing vehicles (eco-routing vs. non ecorouting) increases with the decrease in the $\mathrm{V} / \mathrm{C}$ ratio.

All suggested UE eco-routing strategies may lead to multiple stages of route disequilibrium in terms of travel time. Figure 7 addresses this issue by analyzing route travel times over different deterministic and stochastic scenarios (i.e A and C) of eco-routing vehicles demand and under different levels of saturation. Specifically, Figure 7 quantifies the standard deviation $(\sigma)$, i.e. the dispersion of travel time values among the four routes over the simulated UE assignment procedures. It is possible to observe that $\sigma$ values tend to decrease when vehicles are routed based on travel time ( $\left.\mathrm{UE}_{\mathrm{TT}}\right)$ and tend to increase when vehicles are routed under environmental concerns ( $\mathrm{UE}_{\mathrm{ED}}$ ). Scenarios $\mathrm{A}$ and $\mathrm{C}$ which provide an example in which the eco-routing and non-eco-routing vehicles are stochastically distributed presents an intermediate behavior. In sub scenarios A1 and $\mathrm{C} 1$, after an initial trend to a higher dispersion in routes' travel times (up $750 \mathrm{vph}$ ), it can be seen that the network moves towards a new re-equilibrium as the new incoming vehicles select the fastest route. The opposite trend can be visible in A2 and $\mathrm{C} 2$ sub scenarios. The higher $\sigma$ observed in scenario 
$\mathrm{D} \mathrm{UE}_{\mathrm{ED}}$ is attributed to a rapid increase in the travel time of routes 3 and 4 for higher levels of $\mathrm{V} / \mathrm{C}$ ratios.
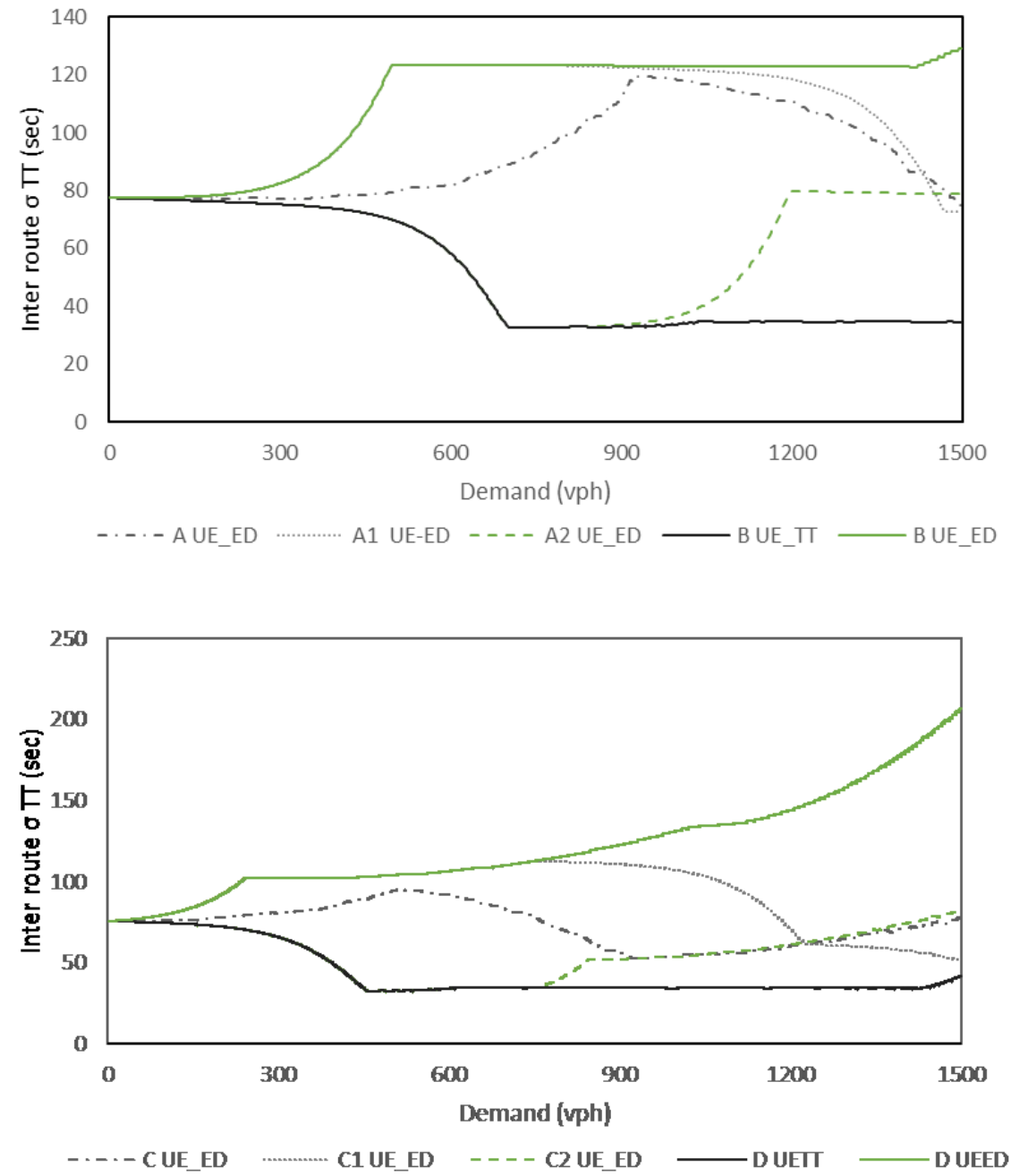

Figure 7. Standard deviation (SD) of inter route travel time for different UE routing scenarios and demand patterns of eco-routing scenarios. Top: Average V/C ratio of $50 \%$. Bottom: Average $\mathrm{V} / \mathrm{C}$ of $80 \%$. The environmental criterion for eco-routing vehicles is environmental damage costs.

Regarding SO assignment, it can be observed that all strategies have a positive impact in 
reducing both emissions and travel time of the study domain. Naturally, the largest reductions are obtained for the parameter directly related to the objective function. Unlike what happens in UE routing procedures, it appears that $S_{\text {TT }}$ is also minimized as a result of a more efficient distribution of traffic flows. The higher emissions savings are recorded for moderate levels of saturation (50\%), and higher levels of acceptance of eco-routing (scenario B) due to the higher available capacity in the network to accommodate different routing strategies. In scenario B, SO routing strategies enables reductions in travel times and emissions from $6.5 \%$ to $9 \%$, due to a transfer of traffic from Route 1 and 4 to Route 2 To identify the traffic volume changes that would be observed in the network, Figure 8 summarizes the variations in traffic distribution among the various routes compared with $\mathrm{UE}_{\mathrm{TT}}$ distribution.
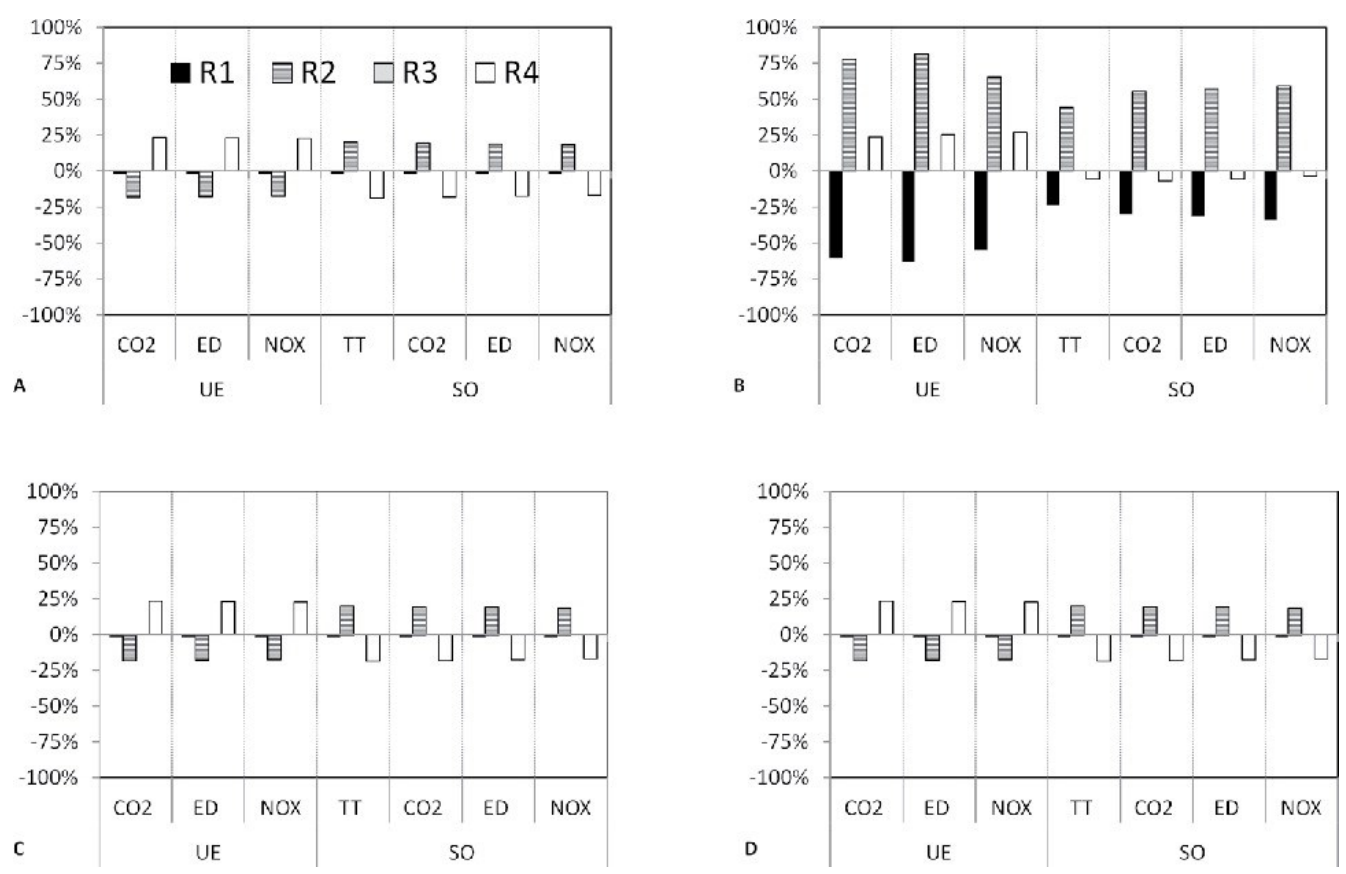

Figure 8 Relative Change in Traffic distribution among the various routes compared with $\mathrm{UE}_{\mathrm{TT}}$ distribution.

In scenarios A, C and D, emissions and travel time savings are reduced substantially as a result of the lower availability of the corridor to accommodate different traffic distributions 
(scenario D) or the lower contribution of eco-routing vehicles (scenarios A and C) to improve network performance.

\section{DISCUSSION AND CONCLUSIONS}

An integrated micro-simulation platform based on state-of-the-art traffic and emissions models and validated with real-world data has been used to generate road segment based volume-emissions-functions. Then, these functions were used to explore eco-route guidance strategies that are appropriate for emissions reduction over a commuting corridor with 4 main alternative routes.

Regarding the UE procedures, it was demonstrated that under certain conditions, the optimization focused on updated information on emissions can lead to worse results than the traditional UE travel time approach. This may not be unconnected to the fact that when drivers are guided with the purpose of minimizing their own travel time, they are guided to high capacity roads. On the other hand, if they are guided to minimize their own environmental impacts, they can be guided to roads with less capacity. Consequently, the marginal impact caused by these vehicles in the remaining vehicles operating on those routes is higher. In these circumstances, the eco-routing information should only be provided ensuring that individual savings outweigh the total potential increases of the remaining vehicles.

For the corridor operating at moderate levels of saturation, 100\% of eco-routing vehicles could generate an overall reduction of $9 \%$ system $\mathrm{CO}_{2}$ and $\mathrm{NO}_{\mathrm{x}}$ emissions when compared with the standard UE travel time. This value tends to be lower (6\% or $4 \%$ ) as the infrastructure is becoming more overfilled or the number of eco-routing vehicles is reduced to half, respectively. Both for eco-routing vehicles and for general traffic, the travel time is not significantly affected. If the objective is to minimize the system environmental damage $\left(\mathrm{S}_{\mathrm{ED}}\right)$ costs, the traffic optimization would allow a reduction of approximately $10 \%$ in $\mathrm{S}_{\mathrm{ED}}$ 
costs. For all cases, this reduction is possible with marginal oscillations (up to 5\%) in travel time of eco-routing vehicles and non-eco-routing vehicles. Under the various UE routing procedures, a trade-off between minimizing travel time and emissions was often observed. However, it appears that this trade-off does not occur in SO routing strategies.

The proposed traffic assignment would force the network to a permanent state of disequilibrium, since the population of eco-routed vehicles would select their route based on updated traffic parameters rather than travel time. Even if assuming that UE is the likely state, it is useful to describe what such an ED or fuel consumption-minimizing state might look like. This methodology and the generated information should be tested in other regions to quantify the impacts of the implementation of eco-routing strategies, and therefore help decision-makers better implement smart mobility plans and intelligent road traffic management policies.

One of the main objectives of this work was to determine the reasons of some previously identified inefficiencies found in previous literature focused on eco-routing strategies. However, further improvements can be made. It will be interesting, as future work, to evaluate the impact of different eco-routing strategies taking into account a more detailed analysis of the individual characteristics of each vehicle. Considering the expected generalization of autonomous vehicles in the coming years, a major research topic will be to assess how smart navigation algorithms can consider the environmental impact of these vehicles (in the case of fossil fuel powered autonomous vehicles), or (most likely) to determine on how autonomous electric vehicles can influence the overall performance of the remaining traffic.

Using performance functions designed ad hoc for each road segment has the advantage of reflecting more accurately the specific constraints of the infrastructure. However, this methodology hinders the generalization of the results. Nevertheless, it may be safe to extrapolate the following evidences:

- Under UE eco-routing strategies, it is likely to happen a trade-off between minimizing travel times and minimizing emission; 
- Counterintuitively, navigation strategies focused on minimizing individual impact may cause adverse effects in urban air quality and traffic performance as eco-routing vehicles tend to be shifted to shorter routes (and probably more densely populated) and whose marginal impact on common traffic is higher;

- The trade-off emissions vs. travel time tend to be minimized under SO routing strategies;

- Eco-traffic management policies should encourage an even and smarter distribution of drivers among alternative routes (e.g. moving towards SO flow by using dynamic pricing/ incentives systems).

\section{ACKNOWLEDGMENTS}

The authors acknowledge the support of the Portuguese Science and Technology Foundation - FCT (grants SFRH/BPD/100703/2014, SFRH/BD/87402/2012 and SFRH/BPD/109426/2015). This work was partially funded by FEDER Funds through the Operational Program "Factores de Competitividade COMPETE" and by National Funds through FCT within the projects PTDC/SEN-TRA/115117/2009 and PTDC/EMSTRA/0383/2014. The authors acknowledge the Strategic Project UID-EMS-00481-2013 and Toyota Caetano Portugal. The work presented in this paper was partially carried out in the scope of the MobiWise project: From mobile sensing to mobility advising (P2O2O SAICTPAC/o011/2015), co-financed by COMPETE 2020, Portugal 2020 - Operational Program for Competitiveness and Internationalization (POCI), European Union's ERDF (European Regional Development Fund), and the Portuguese Foundation for Science and Technology (FCT). J. Bandeira also acknowledges the support of the Project CISMOB (PGI01611), funded by the Interreg Europe Programme. The participation of Dr. Khattak in this research was sponsored in part by the Research and Innovative Technology Administration, U.S. Department of Transportation, through the TranLIVE Tier 1 university transportation centre. The collaboration between Drs. Coelho and Khattak was under the auspices of the Luso-American Transportation Impacts Study Group (LATIS-G).

\section{References}

ACAP. (2012). Automotive Industry Statistics 2010 Edition. ACAP - AUTOMOBILE ASSOCIATION OF PORTUGAL.

Action Plan on Urban Mobility - State of Play. (2012). Brussels,. 
Ahn, K., \& Rakha, H. a. (2013). Network-wide impacts of eco-routing strategies: A largescale case study. Transportation Research Part D: Transport and Environment, 25, 119-130. doi:10.1016/j.trd.2013.09.006

Ahn, K., Rakha, H., \& Moran, K. (2011). System-wide Impacts of Eco-routing Strategies on Large-scale Networks,. In Transportation Research Board 91st Annual Meeting. Washington DC.

Ayyildiz, K., \& Willenbrock, R. (2010). Method and system for traffic control and traffic emission control - EP 2390861 A1.

Bandeira, J. M., Almeida, T. G., Khattak, A. J., Rouphail, N. M., \& Coelho, M. C. (2013). Generating Emissions Information for Route Selection: Experimental Monitoring and Routes Characterization. Journal of Intelligent Transportation Systems, 17(1), 3-17. doi:10.1080/15472450.2012.706197

Bandeira, J. M., Coelho, M. C., Sá, M. E., Tavares, R., \& Borrego, C. (2011). Impact of land use on urban mobility patterns, emissions and air quality in a Portuguese mediumsized city. Science of The Total Environment, 409(6), 1154-1163. doi:http://dx.doi.org/10.1016/j.scitotenv.2010.12.008

Benedek, C. M., \& Rilett, L. R. (1998). Equitable traffic assignment with environmental cost functions. Journal of Transportation Engineering-Asce, 124(1), 16-22.

Boriboonsomsin, K., Barth, M. J., Zhu, W., \& Vu, A. (2012). Eco-Routing Navigation System Based on Multisource Historical and Real-Time Traffic Information. Intelligent Transportation Systems, IEEE Transactions, 13(4), 1694-1704. doi:10.1109/TITS.2012.2204051

Boriboonsomsin, K., Joseph, D., \& Barth, M. (2014). An Examination of the Attributes and Value of Eco - Friendly Route Choices. Transportation Research Record, Journal of the Transportation Research Board, 20427, 13-25.

Borrego, C., Amorim, J.H. Tchepel, O., Dias, D., Rafael, S., Sá, E., Pimentel, C., Fontes, T., 
Fernandes, P., Pereira, S.R., Bandeira, J.M., \& Coelho, M.C. (2016). Urban scale air quality modelling using detailed traffic emissions estimates, Atmospheric Environment, 131, 341351. http://dx.doi.org/10.1016/j.atmosenv.2016.02.017.

Bureau of Public Roads. (1964). Traffic Assignment Manual. (U. P. D. US Dept. of Commerce, Ed.). Washington DC.

Dowling, R., Skabadonis, A., \& Alexiadis, V. (2004). Traffic Analysis Toolbox, Volume III: Guidelines for Applying Traffic Microsimulation Software. Publication FHWA-HRT04-04O. Federal Highway Administration, U.S. Department of Transportation, Washington, D.C.

European Commission - EC. (2011). EG FTF - 1st Report of the Expert Group: Future Transport Fuels.

Ferguson, E. M., Duthie, J., \& Travis Waller, S. (2012). Comparing Delay Minimization and Emissions Minimization in the Network Design Problem. Computer-Aided Civil and Infrastructure Engineering, 27(4), 288-302. doi:10.1111/j.1467-8667.2011.00746.x

Fontes, T., Fernandes, P., Rodrigues, H., Bandeira, J. M., Pereira, S. R., Khattak, A. J., \& Coelho, M. C. (2014). Are HOV/eco-lanes a sustainable option to reducing emissions in a medium-sized European city? Transportation Research Part A: Policy and Practice, 63, 93-106. doi:10.1016/j.tra.2014.03.002

Frey, H. C., Zhang, K. S., \& Rouphail, N. M. (2008a). Fuel use and emissions comparisons for alternative routes, time of day, road grade, and vehicles based on in-use measurements. Environmental Science \& Technology, 42(7), 2483-2489. doi:Doi 10.1021/Es702493v

Frey, H. C., Zhang, K. S., \& Rouphail, N. M. (2008b). Fuel use and emissions comparisons for alternative routes, time of day, road grade, and vehicles based on in-use measurements. Environmental Science \& Technology, 42(7), 2483-2489. doi:Doi 10.1021/Es702493v 
Guo, L., Huang, S., \& Sadek, A. W. (2013). An Evaluation of Environmental Benefits of Time-Dependent Green Routing in the Greater Buffalo-Niagara Region. Journal of Intelligent Transportation Systems, 17(1), 18-30. doi:10.1080/15472450.2012.704336

Gwo Hshiung, T., \& Chien-Ho, C. (1993). Multiobjective decision making for traffic assignment. IEEE Transactions on Engineering Management, 4O(2), 180-187.

Hale, D. How many netsim runs are enough? (1997). McTrans, 11 (3), 1-9

Hongyu, L., S. Guohua, and Y. Lei. A comparison and modification of car-following models for emission estimation. Presented at 95th Annual Meeting of the Transportation Research Board Washington, DC, 2016.

INE. (2012). Portugal Statistics. Retrieved from http://www.ine.pt/

Bandeira J., Carvalho, D. O., Khattak, A. J., Rouphail, N. M., Fontes, T., Fernandes, P., ... Coelho, M. C. (2016). Empirical assessment of route choice impact on emissions over different road types, traffic demands, and driving scenarios. International Journal of Sustainable Transportation. doi:10.1080/15568318.2014.901447

Karoonsoontawong, A., \& Waller, S. T. (2006). Dynamic Continuous Network Design Problem: Linear Bilevel Programming and Metaheuristic Approach. Transportation Research Record: Journal of the Transportation Research Board, 1964, 104-117.

Levin, M. W., Jafari, E., Shah, R., Ruiz-Juri, N., \& Mouskos, K. C. (2014). A Dynamic Traffic Assignment Framework to Assess the Short-Term Network-Level Impacts of Eco-Routing Strategies. TRB 93rd Annual Meeting Compendium of Papers.

Nie, Y., \& Li, Q. (2013). An eco-routing model considering microscopic vehicle operating conditions. Transportation Research Part B: Methodological, 55(0), 154-170. doi:http://dx.doi.org/10.1016/j.trb.2013.06.004

oilprice.com. (n.d.). Retrieved January 22, 2016, from http://oilprice.com/ 
Palacios, J. (1999). Understanding and quantifying motor vehicle emissions with vehicle specific power and TILDAS remote sensing. Department of Mechanical Engineering. Massachusetts Institute of Technology, Cambridge, MA.

PTV. (2005). VISSIM 410 Users' Manual. Karlsruhe, Germany: Planung Transport Verkehr .

Rilett, L., \& Benedek, C. (1994). Traffic assignment under environmental and equity objectives. Transportation Research Record: Journal of the Transportation Research Board, 1443, 92-99.

Smit, R., Brown, a. L., \& Chan, Y. C. (2008). Do air pollution emissions and fuel consumption models for roadways include the effects of congestion in the roadway traffic flow? Environmental Modelling \& Software, 23(10-11), 1262-1270. doi:10.1016/j.envsoft.2008.03.001

Spiess, H. (1990). Technical Note - Conical Volume-Delay Functions. Transportation Science, 24(2), 153-158.

Sundvor, I., Balaguer, N. C., Viana, M., Querol, X., Reche, C., Amato, F., ... Guerreiro, C. (2012). Road traffic's contribution to air quality in European cities. Bilthoven.

US DOT - United States Department of Transportation. (2012). Applications for the Environment: Real-Time Information Synthesis (AERIS).

US Environmental Protection Agency - EPA. (2002). Methodology for Developing Modal Emission Rates for EPA's Multi-Scale Motor Vehicle \& Equipment Emission System. Prepared by North Carolina State University for US Environmental Protection Agency, Ann Arbor . EPA - United States Environmental Protection Agency.

Wismans, L., Berkum, E. Van, \& Bliemer, M. (2013). Effects of Optimizing Externalities Using Cooperating Dynamic Traffic Management Measures on Network Level. Journal of Intelligent Transportation Systems, 17(1), 65-77. doi:10.1080/15472450.2012.716639 
Zhang, Y., Lv, J., \& Ying, Q. (2010). Traffic assignment considering air quality. Transportation Research Part D: Transport and Environment, 15(8), 497-502. doi:10.1016/j.trd.2010.04.011 